\title{
Investigating the Impact of Land Surface Characteristics on Monsoon Dynamics with Idealized Model Simulations and Theories 0
}

\author{
JANE E. SMYTH ${ }^{\mathrm{a}}$ AND Yi MING ${ }^{\mathrm{b}}$ \\ ${ }^{\text {a }}$ Program in Atmospheric and Oceanic Sciences, Princeton University, Princeton, New Jersey \\ ${ }^{\mathrm{b}}$ NOAA/Geophysical Fluid Dynamics Laboratory, Princeton, New Jersey
}

(Manuscript received 10 December 2020, in final form 21 May 2021)

\begin{abstract}
Monsoons emerge over a range of land surface conditions and exhibit varying physical characteristics over the seasonal cycle, from onset to withdrawal. Systematically varying the moisture and albedo parameters over land in an idealized modeling framework allows one to analyze the physics underlying the successive stages of monsoon development. To this end, we implement an isolated South American continent with reduced heat capacity but no topography in an idealized moist general circulation model. Irrespective of the local moisture availability, the seasonal cycles of precipitation and circulation over the South American monsoon sector are distinctly monsoonal with the default surface albedo. The dry land case (zero evaporation) is characterized by a shallow overturning circulation with vigorous lower-tropospheric ascent, transporting water vapor from the ocean. By contrast, with bucket hydrology or unlimited land moisture, the monsoon features deep moist convection that penetrates the upper troposphere. A series of land albedo perturbation experiments indicates that the monsoon strengthens with the net column energy flux and the near-surface moist static energy with all land moisture conditions. When the land-ocean thermal contrast is strong enough, inertial instability alone is sufficient for producing a shallow but vigorous circulation and converging a large amount of moisture from the ocean even in the absence of land moisture. Once the land is sufficiently moist, convective instability takes hold and the shallow circulation deepens. These results have implications for monsoon onset and intensification, and may elucidate the seasonal variations in how surface warming impacts tropical precipitation over land.
\end{abstract}

KEYWORDS: Monsoons; Precipitation; Atmosphere-land interaction; Energy budget/balance; Soil moisture; General circulation models

\section{Introduction}

Monsoon circulations play a key role in Earth's climate, including the atmospheric energy, moisture, and momentum budgets. They are the defining feature of the seasonal cycle over tropical land, producing rain in local summer and dry conditions in winter. Consequently, monsoon variability carries great social and economic significance, with agriculture, energy systems, and ecosystem health all depending on monsoon regularity. Over $70 \%$ of the world's population is directly impacted by monsoon variability, which can cause droughts, floods, food insecurity, worsened wildfires, energy shortages, and broad financial impacts (Zhisheng et al. 2015).

The theoretical and societal importance of monsoons has motivated sustained research efforts to identify the key mechanisms underlying their development and regulation. The traditional conception of monsoons as land-sea breezes has given way to the modern perspective of monsoons as an integral component of the global atmospheric circulation and

๑ Denotes content that is immediately available upon publication as open access.

Supplemental information related to this paper is available at the Journals Online website: https://doi.org/10.1175/JCLI-D-200954.s1.

Corresponding author: Jane E. Smyth, jsmyth@princeton.edu climate. Studies applying the axisymmetric theory for the Hadley cells to idealized monsoons have driven this shift in thinking (Privé and Plumb 2007a,b; Bordoni and Schneider 2008). Based on theory for angular momentum conserving circulations, Privé and Plumb (2007a,b) link the meridional extent of the monsoonal overturning cell to the near-surface maximum of subcloud moist static energy (MSE), and find that this is a good indicator of the monsoon extent even when zonal symmetry is broken. They utilize the MITgcm with Newtonian cooling and prescribed SSTs. Bordoni and Schneider (2008) describe a rapid summertime transition to off-equatorial tropical convergence in an idealized moist aquaplanet model with a two-stream gray radiation scheme. This indicates that land-sea thermal contrast is not fundamental to monsoon emergence. They characterize monsoons as a regime transition of the Hadley circulation: during the monsoon season, the cross-equatorial winter Hadley cell is in an angular momentum-conserving regime, subject to little influence by extratropical eddies. The alignment of streamlines with angular momentum contours over the Indian monsoon sector suggests the potential utility of this theory for off-equatorial monsoons (Bordoni and Schneider 2008).

There are three primary theoretical conceptions of monsoons in the literature: one based on convective quasiequilibrium (CQE), another founded on the MSE budget, and one that frames the monsoon as an extension of the zonalmean ITCZ (Hill 2019). In the CQE view, the monsoonal overturning cell extends to the latitude of highest near-surface 
MSE, with the maximum rainfall located just equatorward thereof (e.g., Privé and Plumb 2007a,b; Nie et al. 2010; Hurley and Boos 2013). CQE posits that convection couples nearsurface and upper- tropospheric MSE, linking high boundary layer MSE to high upper-tropospheric potential temperatures (Emanuel et al. 1994). Within this framework, the impact of a perturbation on the monsoon location can be understood via its effect on the near-surface thermodynamics. While this theory does not explain what controls monsoon strength, Harrop et al. (2019) show that the curvature of subcloud moist entropy could be a strong predictor of precipitation minus evaporation. The CQE paradigm does not seem to hold as cleanly in South America as in other monsoon regions; there is a broad summer maximum of near-surface moist entropy over the continent, with the maximum upper-tropospheric saturation moist entropy located near its poleward boundary (Nie et al. 2010). While useful, the CQE paradigm provides little prognostic power in the absence of a complete theory for what controls the near-surface MSE distribution itself.

Alternatively, some studies use the column-integrated MSE budget as a basis for characterizing tropical rainfall, including monsoon circulations (e.g., Neelin and Held 1987; Chou and Neelin 2004; Back and Bretherton 2006; Neelin 2007; Hill et al. 2017). The MSE budget, presented in detail in section $3 \mathrm{~b}$, states that the net column forcing from radiative and turbulent heat fluxes must balance the atmospheric MSE flux divergence and the time tendency of column-integrated internal energy. While MSE budget analysis is a diagnostic approach, it has been applied in various fruitful ways, such as to evaluate the limits on the poleward extent of monsoons (e.g., Chou and Neelin 2001); to identify key mechanisms of tropical precipitation change, such as the "upped-ante" and "rich-get-richer" responses (Chou and Neelin 2004); and to assess a circulation's susceptibility to these responses under climate change (Hill et al. 2017; Smyth and Ming 2020).

Unlike the local control of precipitation in the CQE and MSE budget theories, the ITCZ framework takes a unified view of land and ocean precipitation as guided by zonal mean energetics (Chao and Chen 2001). This perspective is consistent with a global monsoon mode that encompasses the solstitial migrations of the convergence zone across the regional subsystems (Geen et al. 2020). As in CQE theory, the view of monsoons as a regional extension of the thermally direct Hadley circulation highlights the role of near-surface MSE gradients, rather than temperature gradients, in modulating the monsoon position (Walker et al. 2015). It is also worth noting that the ITCZ over land and ocean may shift in opposite directions in certain situations, hinting at potential limitations of the ITCZ framework (Smyth et al. 2018; Hill 2019).

It is not straightforward to assess the role of land surface properties within any of the aforementioned monsoon theories. Vegetation impacts both albedo and moisture fluxes, driving feedbacks between rainfall changes and ecological transitions (Charney 1975). Soil moisture has implications for the partitioning of surface turbulent fluxes, and therefore the surface temperature, precipitation, and regional circulation (e.g., Seneviratne et al. 2010). In regions with strong landatmosphere coupling, including India, West Africa, and parts of tropical South America (Koster et al. 2004), soil moisture strongly impacts the evaporative fraction and daily maximum surface temperature (Schwingshackl et al. 2018). Zhou and Xie (2018) utilize an idealized model with gray radiation to evaluate the role of geometry, albedo, soil moisture, and ocean heat fluxes on monsoon properties. They find that with the exception of soil moisture, all these factors can be understood via their effects on the surface equivalent potential temperature $\left(\theta_{e}\right.$, essentially MSE) distribution, underscoring the importance of CQE dynamics. In their experiments, soil moisture changes elicit more complex circulation responses that are not always consistent with the migration of the maximum nearsurface MSE, and warrant further study. Zhou and Xie (2018) serves as a useful comparison point for our results as their model differs only in the lower boundary condition and their use of a gray radiation scheme.

Despite the extensive research highlighted above, fundamental questions persist about the theoretical basis of monsoon formation. The complications introduced by zonally confined continental geometry, land surface moisture constraints, and albedo contrasts have yet to be fully elucidated (e.g., Zhai and Boos 2015; Maroon and Frierson 2016; Zhou and Xie 2018; Levine and Boos 2017). The chief purpose of this study is to determine the key mechanisms of monsoon formation across a broad range of climate conditions. The analysis focuses on the processes driving seasonal precipitation that would be relevant beyond the idealized model setting. Motivated by a recent work (Smyth and Ming 2020), we take the summer circulation over South American continental geometry as our focal point, but the analysis aims to elucidate the dynamics of a generic, deep tropical monsoon. In an idealized framework, the experiments map the parameter space of land albedo and moisture conditions, with implications for the stages of seasonal monsoon development as well as the range of global monsoons with their diverse geographic and ecological settings. The holistic approach draws on numerous relevant theories and suggests some general principles regulating monsoon strength. Section 2 describes the idealized moist GCM and the suite of experiments. Section $3 a$ presents the results for varying land moisture conditions, section $3 \mathrm{~b}$ is an MSE budget analysis, and section $3 c$ examines the land albedo perturbation experiments. Section 4 provides an overview of the monsoon formation mechanisms over the range of land surface conditions.

\section{Experimental design}

We use an idealized moist general circulation model as described in Clark et al. (2018). The model has a threedimensional spectral dynamical core, and the highly simplified atmospheric physics largely follows Frierson et al. (2006), including simplified planetary boundary layer and convection schemes. Like Clark et al. (2018), we replace the grayatmosphere radiation used in Frierson et al. (2006) with a full radiative transfer scheme (Paynter and Ramaswamy 2014). This makes it feasible to explicitly simulate water vapor feedbacks. The simplified Betts-Miller (SBM) convection scheme 
has a default convective relaxation time scale $\left(\tau_{\mathrm{BM}}\right)$ of $2 \mathrm{~h}$. This time scale dictates how fast simulated profiles of temperature and humidity are relaxed to convectively adjusted reference states once certain criteria are met (Frierson 2007). The SBM scheme represents shallow, nonprecipitating convection by relaxing unstable temperature profiles to reference profiles, and triggers deep, precipitating convection when moisture and temperature profiles exceed stability thresholds, including a $70 \%$ relative humidity criterion. Precipitation can also form on the grid scale by removing water vapor in excess of saturation. Neither parameterized convection nor gridscale precipitation gives rise to clouds. The impact of cloud feedbacks on the monsoon depends on the net radiative effect of the clouds that form (Voigt et al. 2014); this is a source of uncertainty in climate modeling, and is not considered in the present study. While this compromises the realism of the simulations, it allows for a focus on more essential and robust aspects of the monsoon circulations. In section 4 we compare the results to comprehensive atmospheric model simulations (GFDL AM4.1) that include clouds, topography, and more sophisticated physics, and discuss the relevance of the findings up the model hierarchy.

The lower boundary condition includes a slab mixed layer ocean with a heat capacity equal to $20 \mathrm{~m}$ of water and a prescribed, time-invariant meridional oceanic heat flux, and an isolated South American continent with $10 \%$ of the slab ocean heat capacity (i.e., $2 \mathrm{~m}$ of water). The choice of an isolated continent minimizes the broader climatic impact of land moisture and albedo perturbations by confining them to a comparatively small area, facilitating comparison between experiments. On the other hand, the realistic geometry enables more direct comparison of the monsoon sector with both observations and comprehensive model experiments, including the Geophysical Fluid Dynamics Laboratory (GFDL) AM4 simulations that motivate the present study (Smyth and Ming 2020).

The South American continent has realistic geometry but no topography (i.e., completely flat), and does not include Central America. The exclusion of the Andes mountain range is notable given the attention placed on its climate significance in previous work. For example, the Andes act as a barrier shielding the continent from low MSE oceanic air (e.g., Garreaud and Aceituno 2001) and support low level jet formation both by diverting easterly winds and via lee cyclogenesis (Wang and $\mathrm{Fu}$ 2004). We expect the increased ventilation in the absence of the Andes Mountains to limit the southward extent of the monsoon compared to observations, as in Chou and Neelin (2001).

A suite of experiments forced with a modern-day seasonal cycle of insolation is designed to elucidate the impact of land moisture and albedo conditions on monsoon characteristics. Though the present study focuses on the case of South America as a bridge to the authors' previous work, the use of an idealized model and the focus on mechanistic analysis should yield insights that inform our general understanding of monsoons. The three land moisture configurations include a "realistic" continent (R) with a bucket hydrology model governing potential evaporation, a "dry" (D) continent with zero evaporation, and a "wet" continent (W) in which the land is an infinite reservoir of moisture (i.e., the only distinction between land and ocean is in heat capacity). The bucket hydrology model (Manabe 1969) in the $\mathrm{R}$ configuration scales the potential evaporation based on a bucket capacity (or field capacity) of $150 \mathrm{~mm}$ and a 0.75 saturation fraction, as in Vallis et al. (2018) and Clark et al. (2020). The bucket capacity sets a limit on moisture storage, and the saturation fraction determines that when the bucket level is below $75 \%$ the bucket capacity, the evaporative resistance parameter limits the evaporation to some fraction of the potential evaporation (see (Vallis et al. 2018)).

For each moisture condition, R, D, and W, we perform six albedo perturbation experiments with land albedo prescribed to $0.1,0.26,0.3,0.4,0.5,0.7$, and 1.0 . Note that 0.26 is the default surface albedo over both land and ocean, and is chosen to attain a realistic climate in the absence of clouds (Frierson et al. 2006). The name of an experiment contains a letter (denoting the moisture condition) followed by a number (denoting the albedo). For instance, R0.26 refers to the experiment in which one uses the bucket hydrology model and the default albedo of 0.26 . To discern the effect of the convective relaxation time on the monsoon simulation, we examine three experiments in the R0.26 configuration with $\tau_{\mathrm{BM}}$ varied to 4,8 , and $16 \mathrm{~h}$, as in Clark et al. (2018). The $\mathrm{CO}_{2}$ concentration is prescribed to $369.4 \mathrm{ppm}$, and $\mathrm{CH}_{4}$ to $1.821 \mathrm{ppm}$. The experiments are run at T42 spectral resolution (64 latitude $\times 128$ longitude grid points) with 30 vertical levels. Each simulation is run for 20 years with the final 15 years of daily output used for analysis.

\section{Results}

\section{a. Varying land moisture conditions}

Irrespective of the local moisture availability in the idealized model simulations, the seasonal cycle over the South American monsoon sector $\left(5^{\circ}-18^{\circ} \mathrm{S}, 40^{\circ}-72^{\circ} \mathrm{W}\right)$ is distinctly monsoonal in all three experiments with the default surface albedo (0.26) (Fig. 1a). Modest precipitation commences in October, two to three months after surface temperatures ( $\left.T_{\text {surf }}\right)$ shift to a warming trajectory in late winter (Fig. 1b). With bucket hydrology (R0.26), a maximum rainfall rate of $6.2 \mathrm{~mm} \mathrm{day}^{-1}$ occurs in February, and without a local moisture source (D0.26), the peak monthly mean rainfall of $4.4 \mathrm{~mm}$ day $^{-1}$ occurs a month earlier, in January. When local moisture is unlimited (W0.26), rainfall maximizes at $9.1 \mathrm{~mm} \mathrm{day}^{-1}$ in February. [Throughout the paper, the monsoon season refers to the period from January to March (JFM), the period encompassing the highest mean rainfall rate]. In R0.26, $T_{\text {surf }}$ decreases as precipitation intensifies in JFM because in a moisture-limited regime, latent heat fluxes can increase at the expense of sensible heat fluxes (e.g., Berg et al. 2015). In D0.26 and W0.26, this coupling is eliminated since the local moisture is externally controlled. This may partly explain why $T_{\text {surf }}$ in the dry and wet cases is relatively flat during the monsoon season. In all experiments, precipitation rapidly retreats from April through June, and the dry season extends from July to September (JAS). During this time, there is virtually zero rainfall when local moisture fluxes are limited 

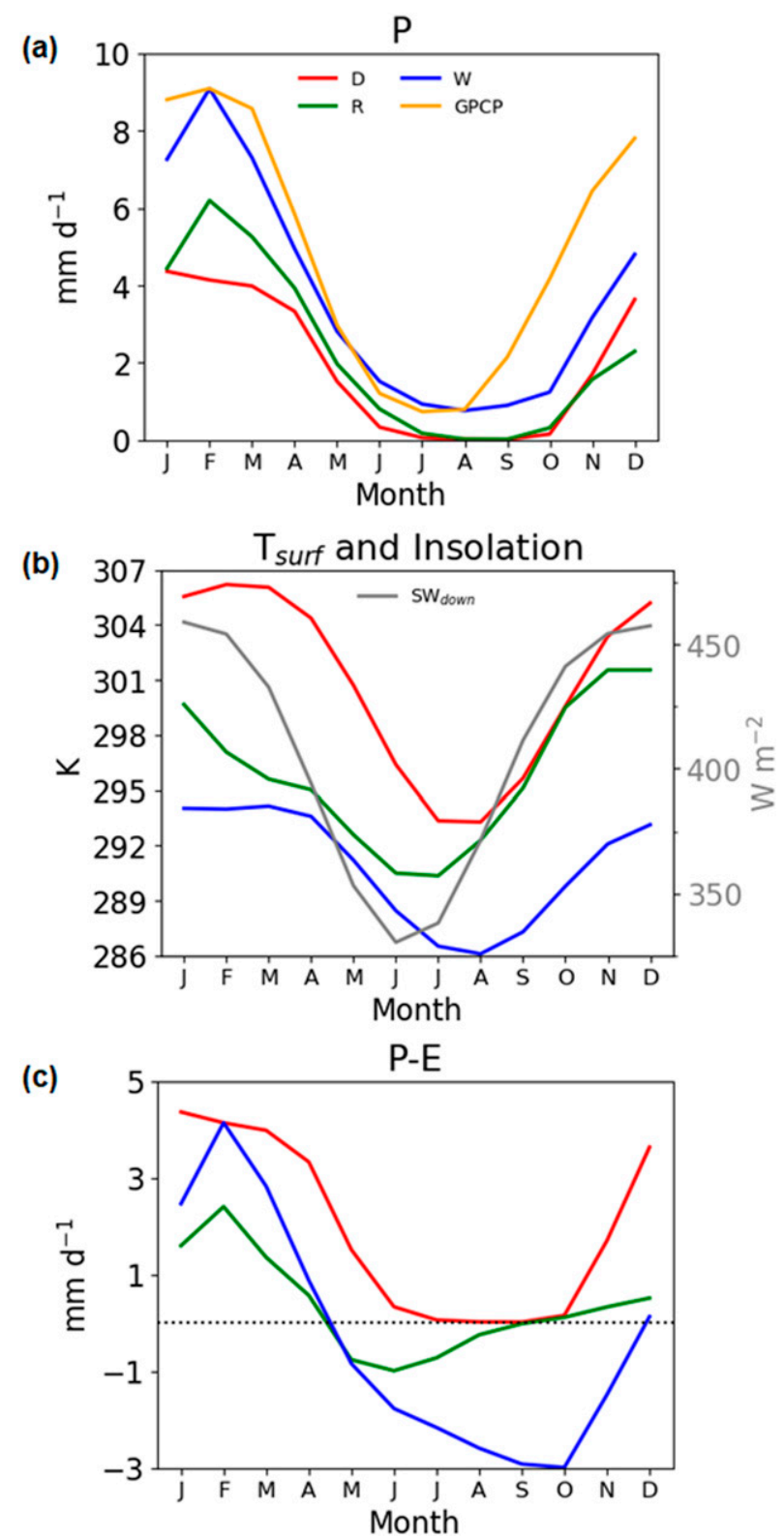

FIG. 1. Seasonal cycles of region-mean (a) precipitation, (b) surface temperature and insolation, and (c) net precipitation $(P-E)$ over the South American monsoon sector in the D0.26, R0.26, and W0.26 experiments.

or disabled, while the mean precipitation hovers around $1 \mathrm{~mm}$ day $^{-1}$ in the W0.26 experiment (Fig. 1a). Insolation minimizes in June, and minimum surface temperatures lag this by 1 month in the R 0.26 and D0.26 experiments and by 2 months in W0.26 (Fig. 1b). In D0.26, surface temperatures respond more strongly to the insolation forcing without the moderating effect of latent heat fluxes on the surface energy balance. The D0.26 experiment exhibits the lowest amplitude annual cycle of precipitation, but the most seasonal variation of surface temperature $(13 \mathrm{~K}$ range, compared to $11 \mathrm{~K}$ in $\mathrm{R} 0.26$ and $8 \mathrm{~K}$ in W0.26).
From a net precipitation perspective $(P-E)$ (equivalent to the large-scale moisture convergence), the rainy season disparity between experiments is smaller, given the substantial enhancement of evaporation in the $\mathrm{R}$ and $\mathrm{W}$ experiments (Fig. 1c). Note that there is no land evaporation in the D experiment, so $P-E$ is the same as $P$. The JFM mean $P-E$ is similar in D0.26 (4.2 $\left.\mathrm{mm} \mathrm{day}^{-1}\right)$ and W0.26 (3.1 mm day $\left.{ }^{-1}\right)$, which underscores the prominent role of the large-scale circulation in importing moisture from the ocean in both extreme cases. The $P-E$ is lower in R0.26 (1.8 $\left.\mathrm{mm}^{\text {day }}{ }^{-1}\right)$; moisture convergence is higher with dry or saturated land than with bucket hydrology. During the dry season, the disparity in $P-E$ is greater than that in precipitation; the JAS mean $P-E$ is negative in $\mathrm{R} 0.26\left(-0.33 \mathrm{~mm} \mathrm{day}^{-1}\right)$ and $\mathrm{W} 0.26\left(-2.6 \mathrm{~mm} \mathrm{day}^{-1}\right)$. In $\mathrm{W} 0.26, P-E$ remains negative into the monsoon onset season (October through December, or OND) before increasing sharply. In the W0.26 simulation this continental region serves as a prominent net moisture source for much of the year, an unrealistic consequence of simulating land without a limit on potential evaporation. Nonetheless, the magnitude and phasing of the precipitation in W0.26 is remarkably similar to the observed 1997-2015 annual cycle from the Global Precipitation Climatology Project v2.3, especially from January to August (Fig. 1a). In this model, a saturated land surface produces the most realistic seasonal cycle of precipitation over the monsoon sector in terms of magnitude and timing; perhaps the saturated land best represents the strong evapotranspiration from vegetation in this region. In all three idealized model experiments the monsoon onset season precipitation is delayed and substantially weaker than observed, underlying a rather abrupt transition.

Despite the simplicity of the model configuration, especially in the absence of the Andes Mountains, the spatial distribution of monsoonal precipitation is largely consistent with observed patterns (Fig. 2), suggesting that the realistic geometry and the differing heat capacity of land and ocean are sufficient to induce a fairly realistic monsoonal climate in the presence of insolation forcing. The key discrepancy in the atmospheric circulation without the Andes is that low-level westerly flow from the tropical Pacific contributes to the continental moisture convergence (Fig. 3). This westerly inflow is particularly strong in D0.26, where a cyclonic circulation on the western continent (Fig. 3a) produces a precipitation maximum near $70^{\circ} \mathrm{W}$, with a relatively narrow rainfall band extending across the width of the monsoon sector (Fig. 2a). Precipitation exceeding $4 \mathrm{~mm} \mathrm{day}^{-1}$ extends from the east coast to $60^{\circ} \mathrm{W}$ in R0.26, with the strongest mean precipitation near $40^{\circ} \mathrm{W}$ (Fig. 2b). When surface moisture is unlimited, the monsoon is coherent with the oceanic intertropical convergence zone (ITCZ) both west and east of the continent, though the precipitation has a broader southward extent over South America (Figs. 2c and 5c).

One notable feature in the simulations is the limited southeastward extension of the South Atlantic convergence zone (SACZ), a convective band that emanates from the Amazon basin over the South Atlantic Ocean. Previous work suggests that the SACZ forms when midlatitude fronts stall at longitudes with enhanced tropical convection and Rossby waves 

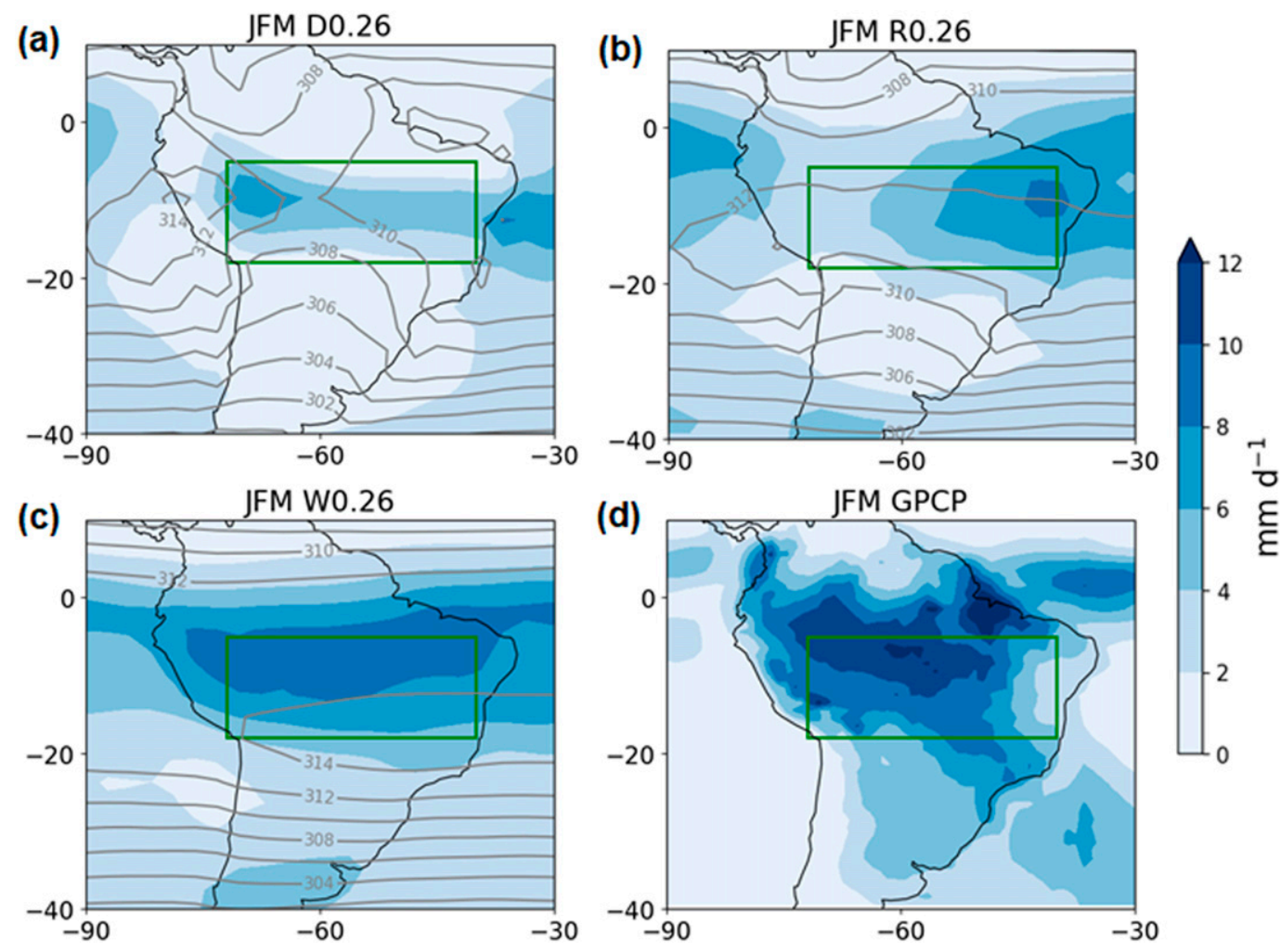

FIG. 2. JFM mean distributions of precipitation (shading; mm day ${ }^{-1}$ ) and 97- hPa MSE (contours; K) in the (a) D0.26, (b) R0.26, (c) W0.26 simulations, and (d) GPCP v2.3 1997-2015 precipitation observations. The green box outlines the monsoon sector.

propagate equatorward (Nieto Ferreira and Chao 2013; van der Wiel et al. 2015). In a series of aquaplanet experiments, Nieto Ferreira and Chao (2013) find that an SACZ-like feature develops when a prescribed patch of enhanced tropical convection attains sufficient strength and poleward extent. In line with Kodama $(1992,1993)$, they emphasize that strong poleward low-level flow on the eastern flank of the monsoon region, or along the west of the subtropical high, is crucial for moisture convergence and SACZ formation. The underdevelopment of the SACZ may be attributed to discrepancies in the location and intensity of such a low-level jet in the idealized simulations. In all three experiments, poleward flow on the eastern coast of the continent does not extend poleward of $15^{\circ} \mathrm{S}$ (Fig. 3). In R0.26 and W0.26, the winds have a northwesterly orientation and are relatively weak, possibly due to the weaker land-ocean thermal gradients.

Like the magnitude of the precipitation, the region-mean near-surface (973 hPa) JFM MSE increases with local moisture availability. The MSE or $h$ is defined as $h=c_{p} T+g z+$ $L_{v} q-L_{f} q_{\text {ice }}$, where $c_{p}$ is the heat capacity of air at constant pressure, $T$ is temperature, $g$ is the gravitational constant, $z$ is geopotential height, $L_{v}$ is the latent heat of vaporization of water, $q$ is specific humidity, $L_{f}$ is the latent heat of fusion of water, and $q_{\text {ice }}$ is specific mass of ice. In D0.26, the nearsurface MSE is lower over the central monsoon sector than the surrounding coastal land, which is mirrored by the precipitation distribution (Fig. 2a). The MSE distribution is more uniform over land and ocean in R0.26 and W0.26 (Figs. 2b,c). In R0.26 the highest near-surface MSE contour bisects the maximum precipitation, and in W0.26, the near-surface MSE is highest just poleward of the strongest precipitation, consistent with CQE theory (Emanuel 1995; Privé and Plumb 2007a; Nie et al. 2010). In section 3c we examine the extent to which the MSE distribution guides the precipitation when land albedo is varied (Hurley and Boos 2013).

While each of these baseline experiments exhibits a monsoonal climate, the precipitation originates via different pathways in the model. With dry land, all moisture for precipitation derives from oceanic regions, so the monsoon sector is particularly reliant on easterly and westerly inflow of moist air from the tropical ocean. With unlimited moisture, the mean JFM evaporation rate is $60 \%$ of the precipitation rate, which points to the substantial local moisture recycling evident from the $P-E$ results. Additionally, in D0.26, the rainy season precipitation $\left(4.2 \mathrm{~mm}\right.$ day $\left.^{-1}\right)$ derives almost exclusively from large-scale processes, with precipitation occurring when an entire grid box reaches saturation (not shown). By contrast, in the R0.26 (5.3 mm day $\left.{ }^{-1}\right)$ and W0.26 (7.8 $\left.\mathrm{mm} \mathrm{day}^{-1}\right)$ experiments, JFM precipitation is largely produced by the parameterized Betts-Miller convection scheme (88\% and $96 \%$, respectively). Given the $70 \%$ relative humidity threshold in the SBM convection scheme, the ratio of convective to large-scale strongly depends on the near-surface humidity (Frierson 2007), a point to which we will return. 
(a)

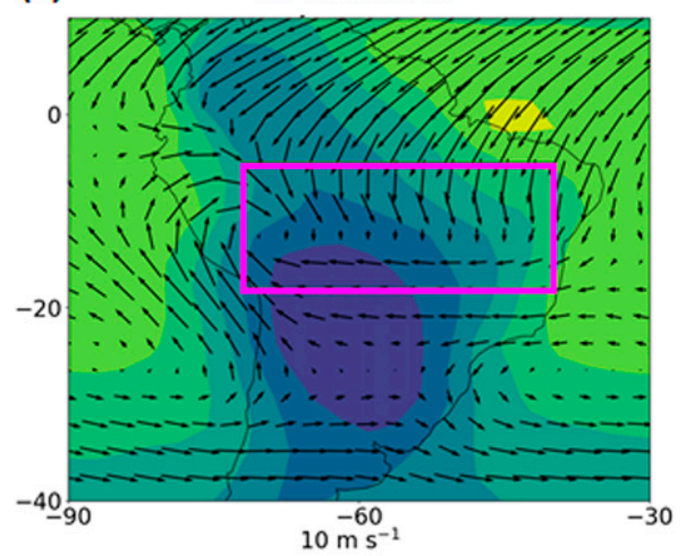

(c)

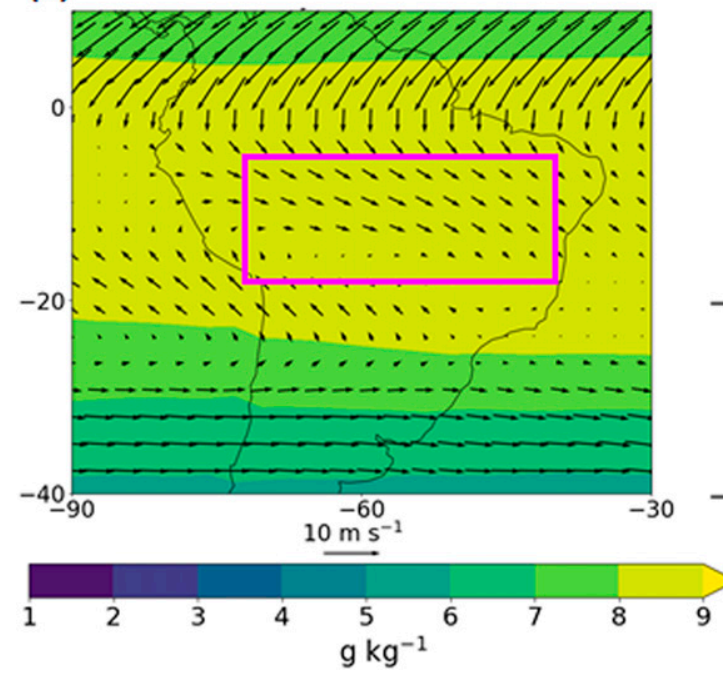

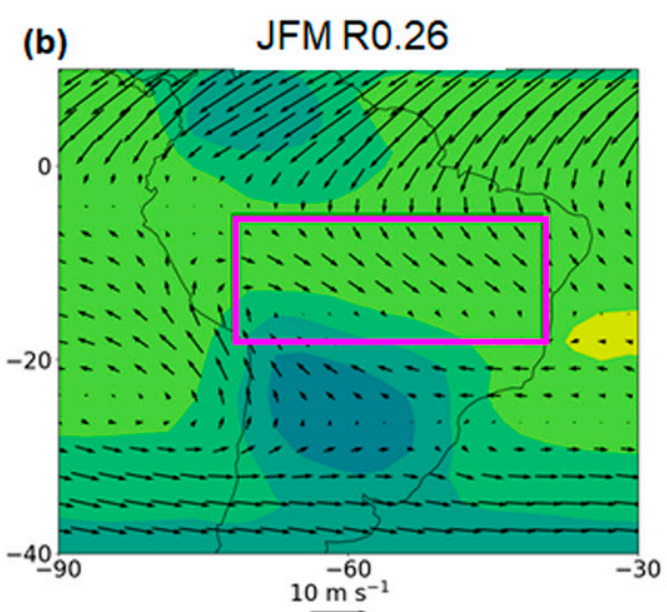

(d) JFM ERA-Interim

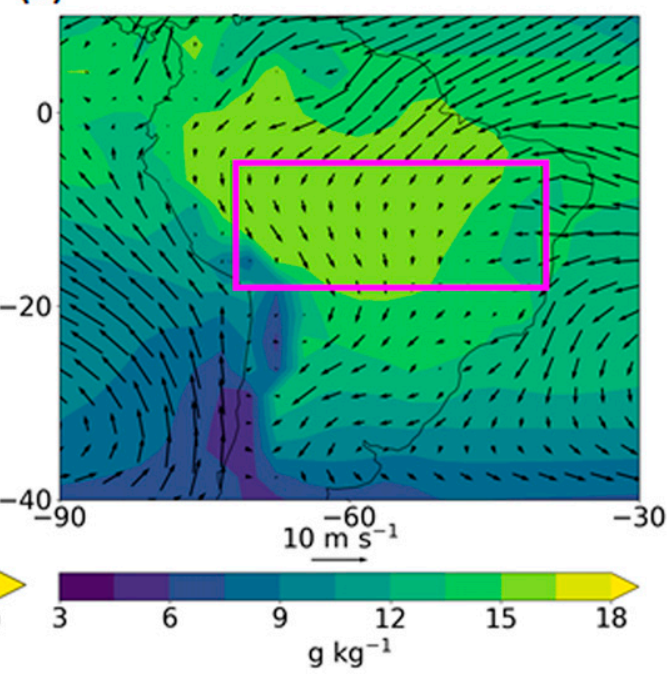

FIG. 3. JFM mean distributions of $920-\mathrm{hPa}$ specific humidity (shading) and horizontal winds (vectors) in (a) D0.26, (b) R0.26, and (c) W0.26, and at $925 \mathrm{hPa}$ and for (d) ERA-Interim, interpolated to the idealized model grid resolution. The model results (a)-(c) use the color bar below (c). The magenta box denotes the monsoon sector.

The underlying large-scale circulation characteristics differ markedly across the range of land moisture conditions. The monsoon-sector mean ascent profiles in the R0.26 and W0.26 experiments indicate top-heavy moist convection that penetrates the upper troposphere, with vertical velocity maxima (50 and $70 \mathrm{hPa}$ day $^{-1}$, respectively) at approximately $400 \mathrm{hPa}$ (Fig. 4a). The dry land case is characteristic of a shallow overturning circulation with vigorous ascent; the maximum vertical pressure velocity $(\omega)$ is $120 \mathrm{hPa}^{-1}$ day $^{-1}$ at $750 \mathrm{hPa}$ (Fig. 4a). Though the ascent profile is relatively shallow, weaker ascent does penetrate to $250 \mathrm{hPa}$.

The region-mean MSE profiles also reflect the differing nature of the monsoon across moisture conditions (Fig. 4b). Although MSE decreases with height in the lower troposphere in all cases before starting to increase, the location of the MSE minimum becomes progressively lower in height with the increasing availability of moisture. Note that the observed tropical MSE profile typically shows a minimum in the midtroposphere (around $600 \mathrm{hPa}$ ) (Back and Bretherton 2006). A possible reason is that the free troposphere in the idealized simulations is biased dry, presumably due to the absence of moistening through convective detrainment of cloud condensates. The comparably low near-surface MSE in D0.26 demonstrates the strong effect of local moisture limitations on the overlying atmosphere.

The R0.26 and W0.26 profiles are firmly under convective quasi-equilibrium (CQE) control, with precipitation produced primarily via the simplified Betts-Miller (SBM) convection scheme. It seems questionable whether this is the case for D0.26, in which the parameterized convection ceases to operate and precipitation is produced exclusively through largescale processes. However, the resolved (gridscale) convection, albeit pathological, may still play a role in establishing a linkage between near-surface and upper-tropospheric MSE. 
(a)

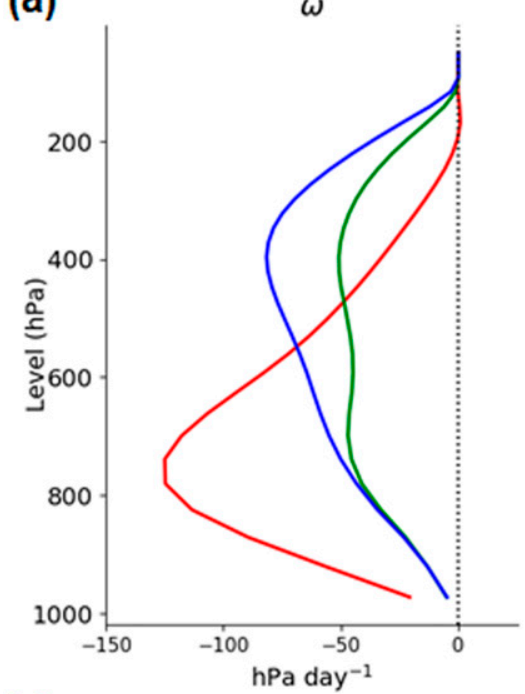

(d)

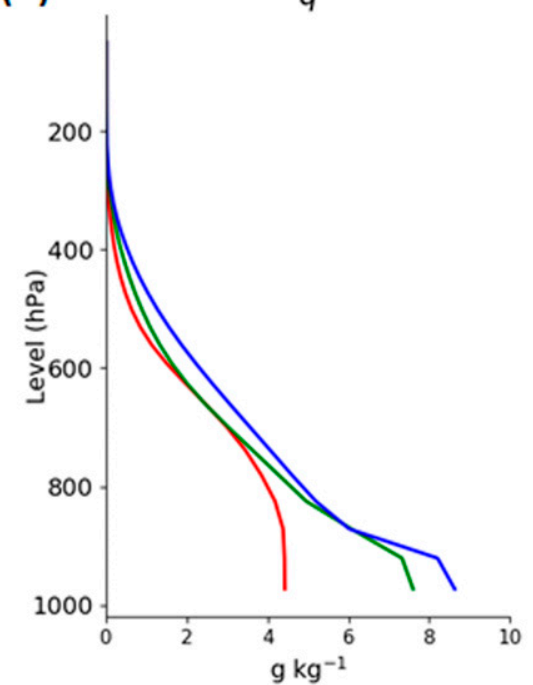

(b)

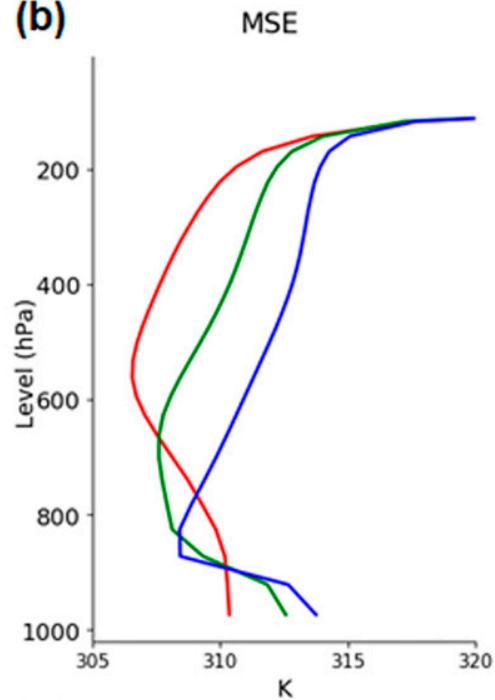

(e)

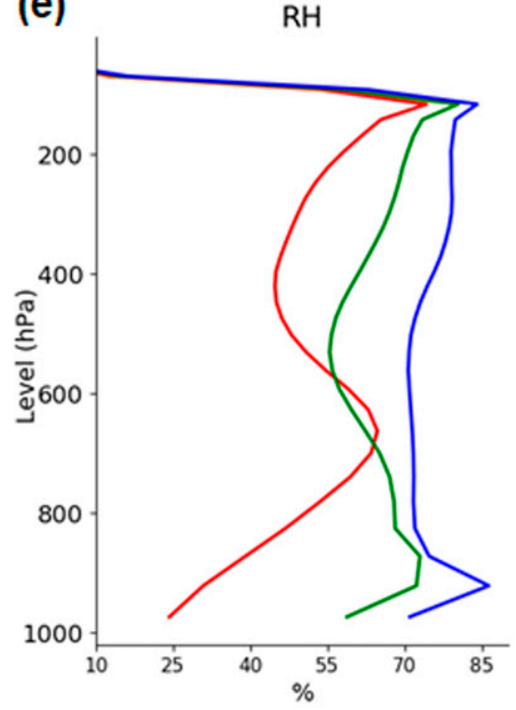

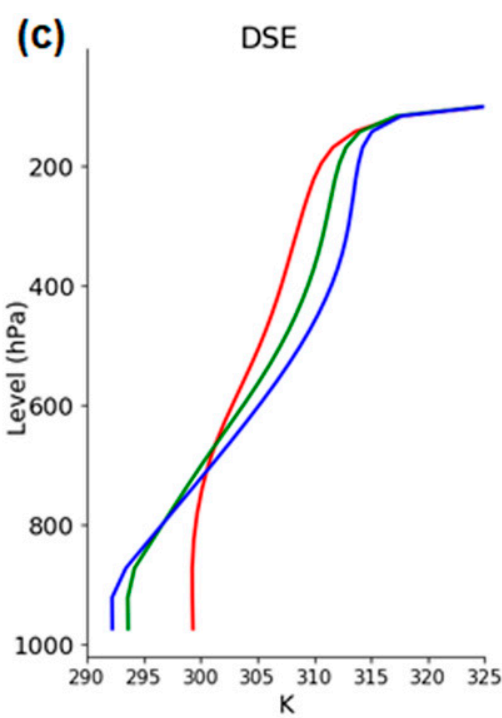

FIG. 4. JFM monsoon sector-mean vertical profiles of (a) vertical pressure velocity, (b) MSE, (c) DSE, (d) specific humidity, and (e) relative humidity in the three baseline experiments.

It is interesting to think about what controls the uppertropospheric MSE in these experiments. CQE states the expectation that in convecting regions, one should see covariation of boundary layer equivalent potential temperature and the upper-tropospheric saturation value (e.g., Nie et al. 2010). The free tropospheric saturation value depends on temperature only, so maxima in boundary layer $\theta_{e}$ should correspond to overlying maxima in free-tropospheric temperature. In the weak temperature gradient (WTG)/CQE framework (e.g., Byrne and O'Gorman 2013; Hill et al. 2017; Zhang and Fueglistaler 2020), the upper-tropospheric MSE throughout the inner tropics is dictated by the highest near-surface MSE. Figure 5 shows that the highest near-surface MSE is located over the land monsoon region and the adjacent ocean in $\mathrm{R} 0.26$ and W0.26. In both cases, the upper-tropospheric temperatures are fairly uniform, varying by less than $3 \mathrm{~K}$ in the inner tropics, as expected due to WTG dynamics (see Fig. S1 in the online supplemental material). The warmest temperatures extend over the monsoonal precipitation and near-surface MSE maxima, in accordance with the CQE framework. In D0.26, the maximum MSE is west of the land precipitation maximum, outside the high-precipitation contours where convection would convey this MSE maximum to the upper troposphere. The D0.26 experiment stands out in that the upper-tropospheric temperature is lowest over the monsoon sector, directly above the local precipitation maximum. The bottom-heavy convection indeed leads to some deviation from CQE conditions over dry land (Fig. 4a). Despite this, continental precipitation in D0.26 appears near the near-surface MSE maximum along the western continental coast (Fig. 5).

The impact of varying land moisture availability is also evident in the vertical distributions of several other key variables. 

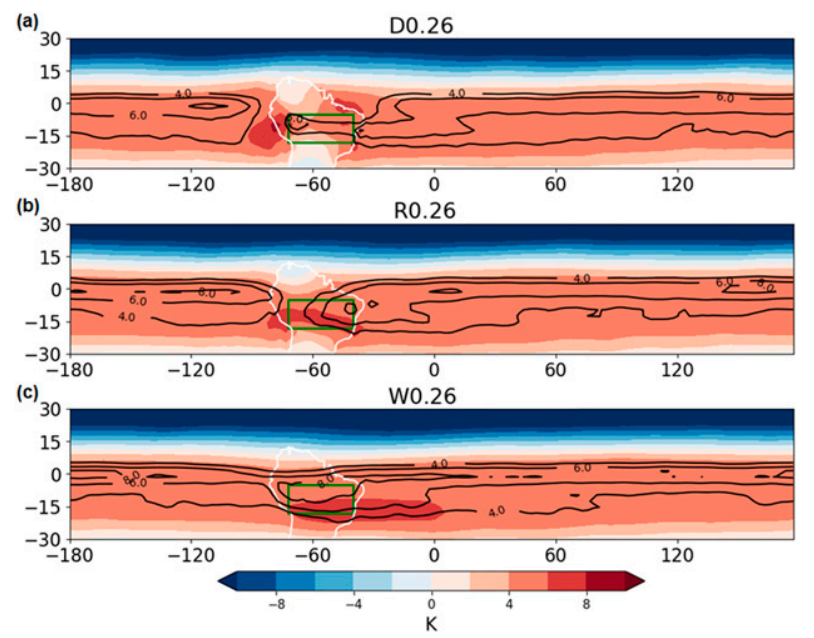

FIG. 5. JFM distributions of the near-surface ( $973 \mathrm{hPa}) \mathrm{MSE}$ minus the tropical mean $\left(30^{\circ} \mathrm{S}-\mathrm{N}\right)$ value (shading) and precipitation (contours; $\mathrm{mm} \mathrm{day}^{-1}$ ) in each of the three baseline experiments. The green box outlines the monsoon sector.

The dry static energy (DSE) profiles reflect hotter nearsurface conditions in the D0.26 experiment as well as a much deeper boundary layer in which quasi-conserved quantities such as DSE are relatively well mixed (Fig. 4c). This homogenization occurs partly via nonprecipitating (dry), shallow convection in the SBM convection scheme (Frierson 2007). Near-surface DSE is highest in the D0.26 experiment and lowest in the W0.26 experiment. By contrast, in the upper troposphere, DSE is highest in the W0.26 experiment and lowest in the D0.26 experiment. As this part of the atmosphere is devoid of moisture (i.e., similar DSE and MSE), it means that the increased availability of land moisture leads to a warming of the upper troposphere. This is a manifestation of the relative standing in near-surface MSE across the experiments which impacts the upper troposphere through convection.

The vertical distribution of specific humidity $(q)$ also varies in these experiments. D0.26 has a much drier boundary layer than R0.26 and W0.26. In all cases, relatively high near-surface moisture values fall off sharply with height at least partly owing to the missing convective detrainment, reducing tropospheric relative humidity values (Figs. $4 \mathrm{~d}$,e). Consistent with these temperature and moisture distributions, the D0.26 experiment has arid near-surface conditions with $25 \%$ mean relative humidity (RH) compared to $60 \%$ and $70 \% \mathrm{RH}$ in the R0.26 and W0.26 experiments, respectively (Fig. 4e), which are sufficiently close to the SBM convective threshold $(70 \%)$. By contrast, it is far too dry for convective precipitation in D0.26. The precipitation intensity distributions also reflect this; in W0.26 the daily rainfall distribution is spread broadly over the $0-20 \mathrm{~mm} \mathrm{day}^{-1}$ range due to frequent moist convection (not shown). In D0.26 by contrast, the distribution has a long tail of infrequent extreme rain events (produced by large-scale scheme), while on the majority of days there is near-zero rainfall.
TABLE 1. JFM column-integrated MSE budget terms $\left(\mathrm{W} \mathrm{m}^{-2}\right)$ averaged over the South American monsoon sector in the D0.26, R0.26, and W0.26 experiments.

\begin{tabular}{lrrr}
\hline & $\mathrm{D} 0.26$ & $\mathrm{R} 0.26$ & $\mathrm{~W} 0.26$ \\
\hline $\bar{F}_{\text {net }}$ & 7.8 & 50.3 & 64.3 \\
$\frac{\partial}{\partial t}\{\overline{\mathscr{E}}\}$ & 3.5 & 3.6 & 3.1 \\
$\left\{\overline{\mathbf{v}} \cdot \nabla_{p} \bar{h}\right\}$ & 5.8 & 9.9 & 6.2 \\
$\left\{\bar{\omega} \frac{\partial \bar{h}}{\partial p}\right\}$ & -23.6 & 21.7 & 43.4 \\
$\nabla \cdot\left\{\overline{h^{\prime} \mathbf{v}^{\prime}}\right\}$ & & & \\
\hline
\end{tabular}

\section{b. MSE budget analysis}

The region-mean MSE budget analysis further illustrates the differing character of the monsoonal circulation in the experiments. The column-integrated MSE budget is given by

$$
\frac{\partial}{\partial t}\{\overline{\mathscr{E}}\}+\left\{\overline{\mathbf{v}} \cdot \nabla_{p} \bar{h}\right\}+\left\{\bar{\omega} \frac{\partial \bar{h}}{\partial p}\right\}+\nabla \cdot\left\{\overline{h^{\prime} \mathbf{v}^{\prime}}\right\} \approx \bar{F}_{\text {net }},
$$

wherein brackets denote mass-weighted column integrals, overbars are time means, primes are temporal deviations, $\mathscr{E}$ is the internal plus potential energy, $\mathbf{v}$ is the horizontal wind vector, $\nabla_{p}$ is the horizontal gradient operator on constant pressure surfaces, $\omega$ is vertical velocity in pressure coordinates, and $\bar{F}_{\text {net }}$ is the net column energy, which equals the sum of topof-atmosphere (TOA) and surface radiative fluxes into the column plus the surface turbulent fluxes.

Based on a calculation of the region mean column-integrated MSE budget (Table 1) following Hill et al. (2017), the vertical MSE advection is negative in the D0.26 experiment, denoting energy import by the circulation, and positive in the R0.26 and W0.26 experiments. In all three cases, the DSE component of the vertical MSE advection term is positive, since DSE increases with altitude, while the moisture component is negative. Only in the D0.26 experiment does the latter dominate. Between 600 and $800 \mathrm{hPa}$ the vertical moisture gradient, decreasing with altitude, is sampled by very strong vertical velocity values.

The negative $\{\bar{\omega} \partial \bar{h} / \partial p\}$ in D0.26 corresponds to a negative gross moist stability (GMS). The GMS relates the column energy transport to the strength of the mean circulation and can be thought of as the efficiency of a circulation's energy export (Bretherton et al. 2006). It is determined by the structure and amplitude of the vertical velocity, along with the stratification of the MSE. In this sense, the D0.26 monsoon circulation is similar in nature to the observed east Pacific ITCZ, a region of relatively shallow precipitating convection with a negative GMS (Back and Bretherton 2006). By contrast, the monsoon dynamics in R0.26 and W0.26 resemble the deep convection of the west Pacific ITCZ, with positive vertical MSE advection values denoting energy export. These circulations comply with the Neelin and Held (1987) theory of tropical rainfall in which vertical MSE advection plays a chief role in balancing column heating, and precipitating tropical convection is associated with a positive GMS. 


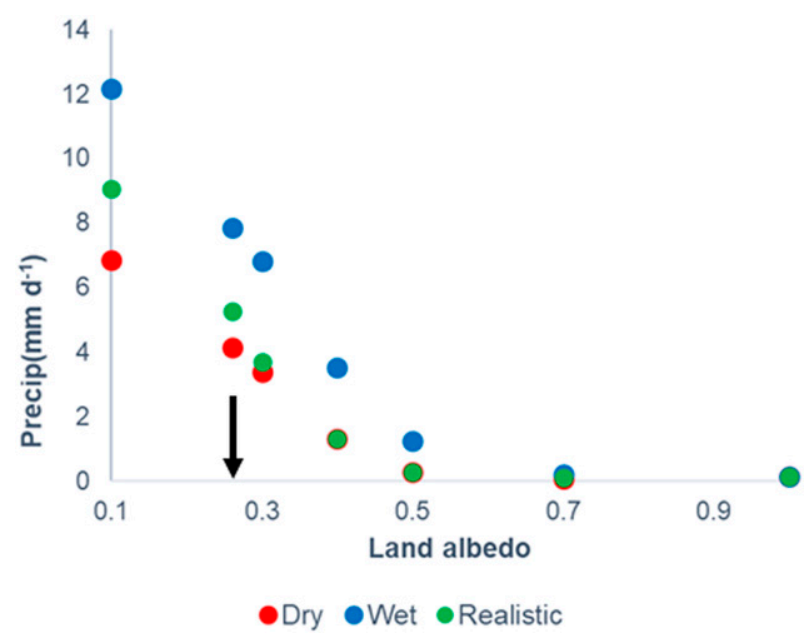

FIG. 6. JFM mean precipitation in the monsoon sector as a function of land surface albedo with dry, wet, and realistic surface moisture conditions. The black arrow indicates the control albedo value of 0.26 .

The horizontal MSE advection term is similar across the three experiments, between 5 and $10 \mathrm{~W} \mathrm{~m}^{-2}$, and contributes to MSE export in each case. A decomposition of the horizontal MSE advection into dry and moist components, however, reflects differences between the experiments. In D0.26, the advection of relatively cool, moist air from the adjacent ocean produces a positive horizontal DSE advection $\left(\left\{\overline{\mathbf{v}} \cdot \nabla_{p} \overline{\mathrm{DSE}}\right\}=39.2 \mathrm{~W} \mathrm{~m}^{-2}\right)$ and a negative column horizontal moisture advection $\left(\left\{\overline{\mathbf{v}} \cdot \nabla_{p} \overline{L_{v} q}\right\}=-33.7 \mathrm{~W} \mathrm{~m}^{-2}\right)$. In the R0.26 and W0.26 configurations, the region mean horizontal DSE advection is near zero $\left(2.4\right.$ and $\left.-0.1 \mathrm{~W} \mathrm{~m}^{-2}\right)$, while the horizontal moisture advection is positive, denoting export $\left(7.8\right.$ and $\left.6.4 \mathrm{~W} \mathrm{~m}^{-2}\right)$. These results indicate a relatively small land-sea temperature contrast and higher specific humidity over land than over ocean. The value of $F_{\text {net }}$ differs by an order of magnitude between the experiments, ranging from $7.8 \mathrm{~W} \mathrm{~m}^{-2}$ in D0.26 to $64 \mathrm{~W} \mathrm{~m}^{-2}$ in $\mathrm{W} 0.26$. This is due primarily to differences in outgoing longwave radiation (OLR), with higher surface temperatures and thus OLR over dry land. The impact of the net column energy flux on the regional climate is examined further in the analysis of the albedo perturbation experiments.

The budget analysis demonstrates that in all three baseline experiments, precipitation is generated by the mean flow rather than transients. Mean ascent in the monsoon sector drives moisture convergence and precipitation, while transient eddies diverge moisture. The eddy MSE flux divergence is dominated by the moisture contribution in all three experiments, and the DSE component is negative in R0.26 and W0.26, indicating DSE convergence over the monsoon sector. The predominance of the mean circulation in generating precipitation is further supported by an assessment of the JFM mean potential vorticity (PV) distribution over continental longitudes (not shown). A necessary condition for baroclinic instability is a reversal of the meridional PV gradient (Charney and Stern 1962; Hsieh and Cook 2005), and this is not satisfied in $\mathrm{D} 0.26$ or $\mathrm{W} 0.26$. In $\mathrm{R} 0.26$, a PV gradient reversal at $600 \mathrm{hPa}$ along the southern margin of the monsoon sector suggests a possible role for baroclinic instability. Rayleigh's criterion for barotropic instability (a change in sign of $\beta-u_{y y}$ ) is not satisfied in any of the three baseline experiments (not shown).

\section{c. Land albedo perturbation experiments}

To better understand the impact of net column energy fluxes on monsoon characteristics, as well as the limits of monsoonal climate regimes, we examine a suite of land albedo perturbation experiments. Land albedo variations drastically impact the monsoonal precipitation magnitude (Fig. 6), in agreement with previous studies (Zhou and Xie 2018; Boos and Storelvmo 2016). With all three moisture conditions, JFM precipitation declines monotonically with increasing land albedo, with minimal rainfall at albedo values of 0.5 or higher. Regardless of local moisture availability, when the albedo is increased to 0.7 or 1.0 , the monsoon region is subject to mean descent throughout the atmospheric column (Fig. 7).

The surface temperatures over land in the R0.5 and D0.5 experiments (296 and $301 \mathrm{~K}$, respectively) remain higher than adjacent SSTs, so that a weak, viscously driven circulation persists, though it produces negligible precipitation (Figs. 6 and $7 \mathrm{a}, \mathrm{b})$. In the $\mathrm{R}$ and $\mathrm{D}$ experimental suites, ascent is confined to the boundary layer when albedo values are prescribed to 0.4 or 0.5 (Figs. 7a,b). In these simulations, the surface temperature distributions induce low-level pressure gradients which drive convergence over the monsoon sector. In the lower range of land albedo values, the $\mathrm{R}$ and $\mathrm{D}$ experiments diverge. In the D0.3, D0.26, and D0.1 experiments, the ascent grows increasingly vigorous and vertically extended. While the ascent maximum is relatively low in each of these experiments (below $650 \mathrm{hPa}$ ), the ascending motion extends through the midtroposphere, and is accompanied by a jump in precipitation intensity with mean values of $3.4,4.2$, and $6.9 \mathrm{~mm} \mathrm{day}^{-1}$, respectively, compared to $1.3 \mathrm{~mm}$ day $^{-1}$ in the D0.4 experiment (Fig. 6). Even when land albedo is lowered to 0.1 in the dry land configuration, the precipitation derives almost exclusively from the large-scale scheme. By contrast, in the R0.3, R0.26, and R0.1 experiments, deep convection develops and precipitation increases to $3.7,5.3$, and $9.1 \mathrm{~mm} \mathrm{day}^{-1}$, respectively. The shape of the ascent profiles and the proportion of convective to total precipitation support that convective instability underlies the monsoon development in these $\mathrm{R}$ experiments.

In the wet land configuration, land albedo variations do not alter the precipitation mode; in any experiment in which land remains thermodynamically favorable, precipitation is driven almost exclusively by convective instability. In W0.1 the vertical velocity profile strengthens, and when the land albedo is increased to 0.3 or 0.4 , convection weakens but remains vertically extensive (Fig. 7c). In the W0.5 experiment, without land-ocean gradients in surface moisture availability, the albedo perturbation reduces the temperature of land to $290 \mathrm{~K}$, below that of the nearby sea surface, resulting in mean descent through the column (Fig. 7c). Boundary layer confined ascent only develops in the simulations with land moisture limitations. 

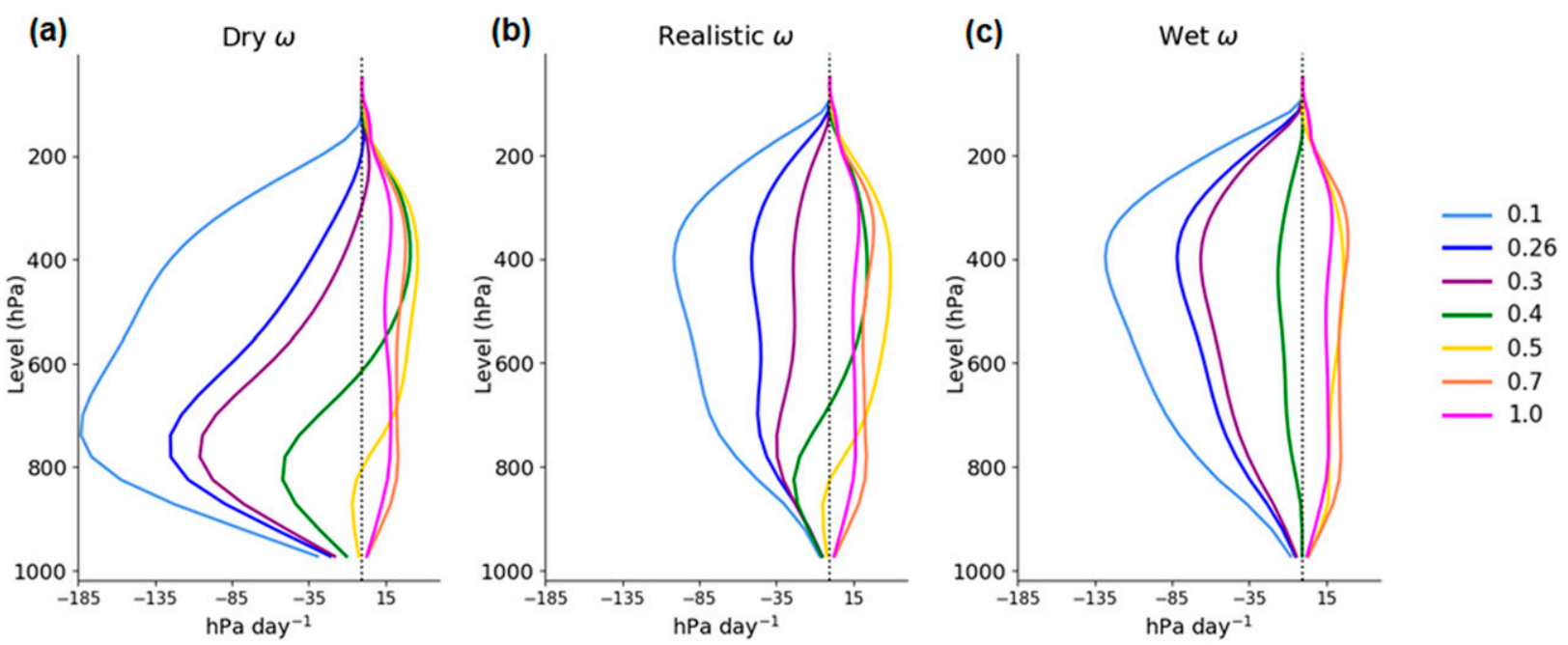

FIG. 7. JFM mean vertical profiles of the vertical pressure velocity over the monsoon sector as land surface albedo is varied in the (a) dry, (b) realistic, and (c) wet land surface moisture experimental suites.

We consider the hypothesis that inertial instability underlies the enhancement of the monsoonal circulation in the three dry low-albedo experiments (i.e., D0.3, D0.26, and D0.1) (Plumb and Hou 1992; Tomas and Webster 1997). The near-surface $(920 \mathrm{hPa})$ absolute vorticity $(\eta)$ distribution supports this, as the zone of locally anticyclonic absolute vorticity expands with the off-equatorial migration of the $\eta=0$ contour over continental latitudes when albedo is reduced below 0.4 (Figs. 8a,b). In inertially unstable zones, the divergent wind accelerates to generate a locally cyclonic tendency term, relaxing the instability. The resulting convergence zone intensifies local convection and precipitation. In the three low-albedo experiments, the nearsurface divergence over the central continent is predominantly equatorward of $\eta=0$, with the convergence zone largely lying poleward thereof, consistent with Tomas and Webster (1997) (Figs. 8a,b). This is not the case in the higher albedo experiments, including D0.4 and D0.5, in which the continental convergence zone straddles the $\eta=0$ contour which hovers closer to the equator (Figs. 8c,d). Furthermore, the highest 920-hPa divergent wind speeds are bisected by the $\eta=0$ contour when it deviates poleward over the continent in the D0.3, D0.26, and D0.1 experiments (Fig. S5). In D0.4 and D0.5, the maximum divergent wind speeds over continental longitudes occur north of the equator (Fig. S5).

In the $\mathrm{R}$ and $\mathrm{W}$ experimental suites, inertial instability seems to play a less central role in monsoon development. In February,
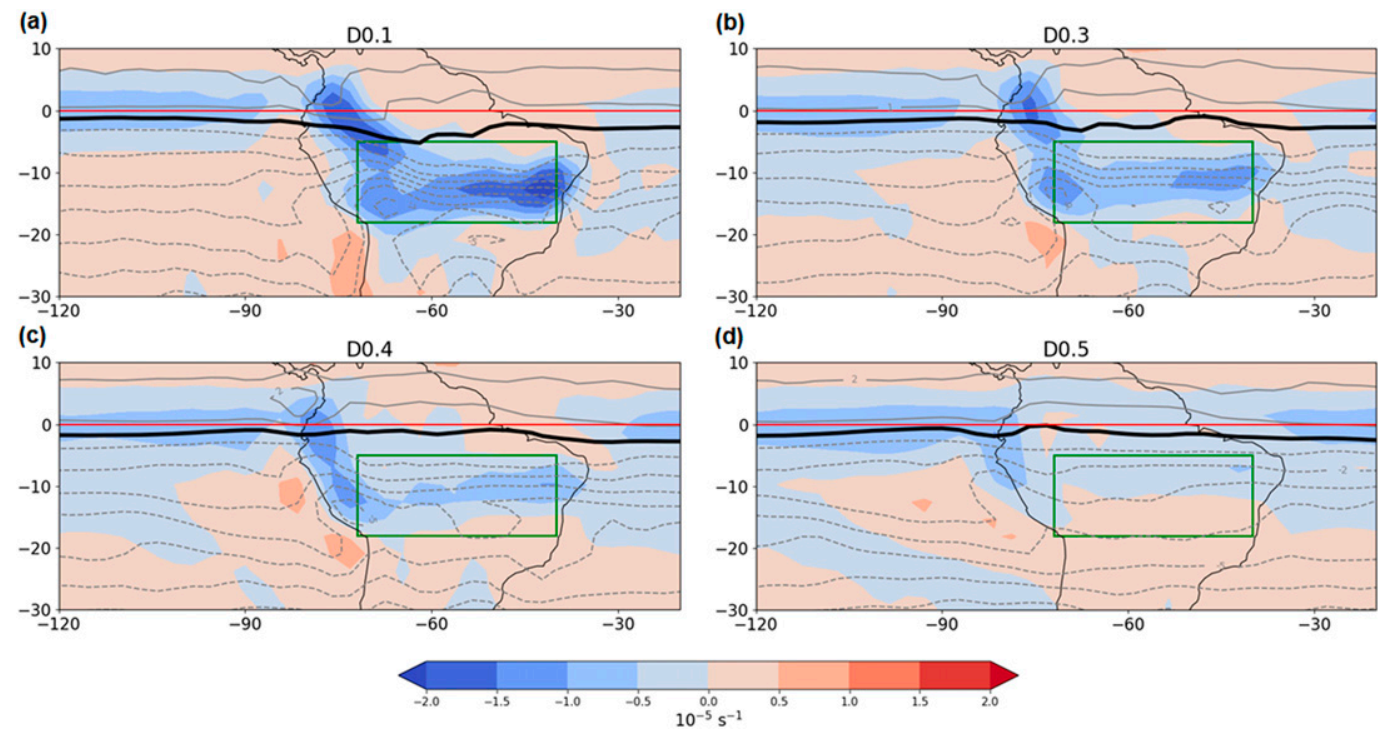

FIG. 8. February 920-hPa absolute vorticity (contours) and divergence (shading) in the (a) D0.1, (b) D0.3, (c) D0.4, and (d) D0.5 simulations. The bold black line is the zero line of absolute vorticity. The green box outlines the monsoon sector. 
the $\eta=0$ contour migrates only slightly farther poleward over the continent than over the adjacent ocean, and the displacement is smaller than in the dry land experiments (not shown). For example, in D0.26, the maximum southward displacement of the contour over the continent is $4.2^{\circ}$, compared to $2.4^{\circ}$ in the $\mathrm{R} 0.26$ experiment and $2.7^{\circ}$ in W0.26. This disparity may be explained by the relatively strong cross-equatorial pressure gradient in the dry land experiments caused by the particularly strong heating of the continent.

In terms of the spatial distribution of precipitation, the effect of albedo variations depends on the land moisture configurations (Figs. S2-S4). In the D configuration, the near-surface MSE maximum does not shift substantially in response to albedo perturbations. Correspondingly, there is little latitudinal change in the monsoon location. At lower albedo values in the $\mathrm{W}$ configuration, and to a lesser extent in $\mathrm{R}$, the near-surface MSE maximum increases and shifts poleward, and the monsoon expands poleward, in accordance with CQE predictions (Hurley and Boos 2013). In both the R and W experiments, JFM precipitation is strongest near the Atlantic coast, and as the continent heats up at lower albedo values, the monsoon penetrates farther westward over the continent. Increased continental heating and thermal gradients can enhance baroclinicity of prevailing easterlies and thus convective storm formation, driving a westward expansion of the monsoon; such a process underlies the strengthening of African Easterly Wave activity in global warming simulations (Skinner and Diffenbaugh 2014). The spatial pattern of precipitation differs in the D suite; a local precipitation maximum near the west coast, coinciding with a local MSE maximum, emerges when the land albedo is 0.3 or lower (Fig. 5). The thermal low over the continent induces convergence of westerly winds from the Pacific and easterly winds from the Atlantic. These lowertropospheric winds are stronger in the $\mathrm{D}$ suite than the corresponding $\mathrm{R}$ and $\mathrm{W}$ experiments due to the relatively strong land-sea thermal contrast (Fig. 3). With realistic topography, this moist westerly inflow would be impeded by the Andes.

When land surface albedo is varied across a broad range, various types of monsoonal circulations arise. At the highest albedo values, the land surface is cooler than the zonal mean value and the monsoon vanishes. At moderate albedo values, a viscously driven circulation emerges in local summer, producing a modest seasonal cycle of precipitation over offequatorial South America. When albedo is reduced to 0.4 or below, inertial instability triggers enhanced convergence and precipitation in the dry land experiments, while convective instability produces more substantial rainfall in the realistic and wet land configurations. Even when the land albedo is suppressed to 0.1 , the absence of latent heat fluxes leads to an exceedingly dry boundary layer and inhibits parameterized moist convection in the dry land experiment. It is notable that even without triggering parameterized convection, the JFM precipitation in D0.1 is substantial $\left(6.9 \mathrm{~mm} \mathrm{day}^{-1}\right)$ and exceeded only by the W0.26, W0.1, and R0.1 experiments (7.8, 12.2 , and $9.1 \mathrm{~mm} \mathrm{day}^{-1}$, respectively). When $F_{\text {net }}$ is sufficiently strong due to the sensible heat flux, moisture transport and convergence partially compensate for the disabling of local moisture recycling. Evidently, while a local moisture limitation shapes the monsoonal regime, this parameter alone does not impede the monsoon's emergence nor its intensification. This has implications for monsoon onset, which occurs when local moisture availability is constrained following the dry season in South America. Throughout the spring, increasing local soil moisture and latent heat fluxes enable the vigorous convection of the monsoon season (Fu and Li 2004). The processes driving the initial precipitation that primes the region for monsoon development may resemble the mechanisms in the D suite (i.e., inertial instability).

Regardless of the physics underlying precipitation development across the suite of experiments, the JFM precipitation increases nearly linearly with $F_{\text {net }}$, suggesting that this is a key parameter modulating monsoon intensity (Fig. 9a). Moderate precipitation develops only when $F_{\text {net }}$ values exceed zero. While local moisture conditions circumscribe the physical triggers of convection, in any case the magnitude of the precipitation is related to the magnitude of the MSE flux divergence. The circulation must comply with the MSE budget, meaning the MSE flux divergence by the total circulation (horizontal advection, vertical advection and eddies) must balance the net forcing and the time tendency (the latter changes negligibly). A higher net column forcing necessitates a stronger mean circulation and/or more pronounced MSE gradients on which the circulation acts. In the dry land experimental suite, the circulation strength (using vertical pressure velocity as a proxy) increases drastically as albedo is reduced, supporting more moisture import and stronger convergence (Fig. 7a). In the experiments with higher land moisture availability, the circulation strength also increases with the net column forcing, albeit more modestly. In each suite of experiments, there is a concomitant enhancement of precipitation. This relationship between precipitation and net column forcing aligns with the findings of Boos and Storelvmo (2016), who demonstrate that monsoon strength has a nearly linear dependence on radiative forcing in both a comprehensive GCM and an analytical model.

Examining the TOA components of the net forcing term, the relationship between precipitation and net shortwave radiation is more consistent among experiments than the relationship between precipitation and OLR (not shown). As described earlier, the OLR is consistently higher in the dry land experiments due to the restrictions imposed on the land surface energy budget. By the same reasoning, the region-mean OLR at a given precipitation rate is consistently lower in the wet land experiments than the $\mathrm{R}$ experiments.

To better compare thermodynamic conditions given these moisture-modulated differences in the surface energy budget, we examine the relationship between near-surface $\theta_{e}$ and precipitation. In all three configurations, as albedo decreases, precipitation increases accompany increases in both the continental near-surface $\theta_{e}$ and its horizontal gradient (Figs. 9b,c). This underscores that a positive relationship between the amplitude of precipitation and near-surface $\theta_{e}$ can persist even when parameterized convection is largely inactive (Fig. 9b). Figure 9b illustrates a threshold behavior: all experiments with region-mean $\theta_{e}$ below $302 \mathrm{~K}$ have negligible precipitation. In the remaining experiments, in which region-mean $\theta_{e}$ values 

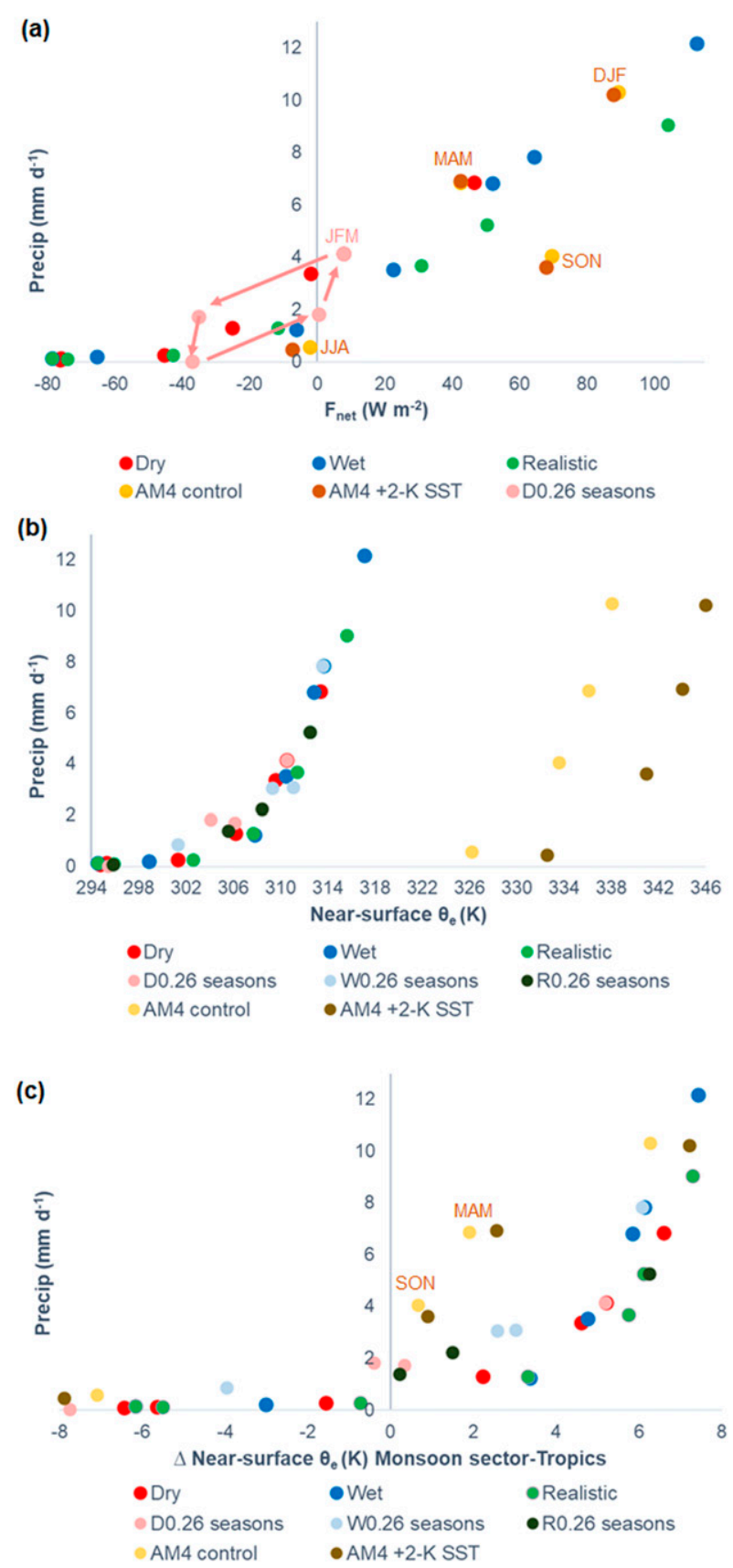

FIG. 9. JFM mean precipitation in the monsoon sector as a function of (a) net column energy and (b) 973-hPa $\theta_{e}$ in all land surface albedo and moisture perturbation experiments. The plot in (a) also includes the data for all four seasons of the GFDL AM4 control and +2-K SST warming experiments (labeled in the plot), as well as the four seasons of the D0.26 experiment (JFM, AMJ, JAS, OND). The plot in (b) includes the seasonal data for the three baseline experiments.

range from 306 to $313 \mathrm{~K}$, precipitation steadily increases with $\theta_{e}$ regardless of the land moisture condition. Figure $9 \mathrm{c}$ is relevant for understanding this threshold behavior: the onset of appreciable monsoonal precipitation occurs when the monsoon sector region-mean near-surface MSE approaches or exceeds the tropical mean value. It is striking that this relationship holds in the dry land experiments, given the impedance of parameterized convection, the shallow ascent profile (Fig. 4a), and the disruption of CQE conditions in the atmosphere (Fig. S1), as in Zhou and Xie (2018).

\section{Discussion}

The suite of idealized model experiments demonstrates the profound impact of land surface conditions on monsoon dynamics. These experiments, and the precipitation mechanisms they reveal, may inform our understanding of the stages of monsoon development on Earth. As an example, we consider the seasonal cycle over the South American monsoon sector as simulated in the GFDL AM4 model with prescribed climatological SSTs. In previous work, the authors examined the seasonally varying responses of precipitation in the South American monsoon sector to uniform 2-K SST warming in the GFDL AM4 model (Smyth and Ming 2020). Though the spring and fall are both characterized by moderate precipitation rates and similar region-mean MSE budget regimes in AM4, they exhibit different responses to warming. Spring rainfall decreases by $11 \%$ and $P-E$ decreases by $40 \%$, while fall rainfall remains unchanged. This difference is linked to the difference in the climatological low-level relative humidity, which is $60 \%$ in spring and $80 \%$ in fall. The seasonal contrast in $\mathrm{RH}$ impacts the surface temperature and boundary layer MSE distributions and leads to different anomalous patterns in the SST warming experiment. Ultimately, the more pronounced land-sea contrast in spring renders the season vulnerable to drying by anomalous horizontal MSE advection in the $+2-\mathrm{K}$ experiment. The study concludes that differing boundary layer humidity plays a crucial role in setting the monsoon properties and thus the sensitivity to perturbations. This echoes Byrne and O'Gorman (2015), who find that changes in the horizontal gradients of temperature and fractional changes in relative humidity explain why the $P-E$ response over land deviates from the canonical wet-get-wetter scaling. To what extent can the idealized model results shed light on these findings?

To assess whether the linear relationship between net column heating and precipitation holds beyond the idealized modeling framework, Fig. 9a includes the data points for the four seasons in AM4 control and $+2-\mathrm{K}$ experiments. The seasonal cycle in AM4 exhibits hysteresis in this parameter space (Fig. 9a). In SON, preceding the rainy season, the AM4 control net column heating is $69.5 \mathrm{~W} \mathrm{~m}^{-2}$ and the precipitation rate is $4.1 \mathrm{~mm}$ day $^{-1}$. Following the rainy season, in MAM, the net column heating is lower $\left(42.5 \mathrm{~W} \mathrm{~m}^{-2}\right)$ while the precipitation rate is higher $\left(6.9 \mathrm{~mm} \mathrm{day}^{-1}\right)$. As noted above, the shoulder seasons have similar MSE budget regulation regimes, as characterized by the relative strength of vertical to horizontal MSE advection (Smyth and Ming 2020). Mapping the seasonal cycle in Fig. 9a points to the impact of the differing surface moisture availability on the efficiency of precipitation production. SON exhibits a clear deviation from the largely linear relationship across the idealized experiments and the other AM4 seasons (Fig. 9a). Based on net column heating, 


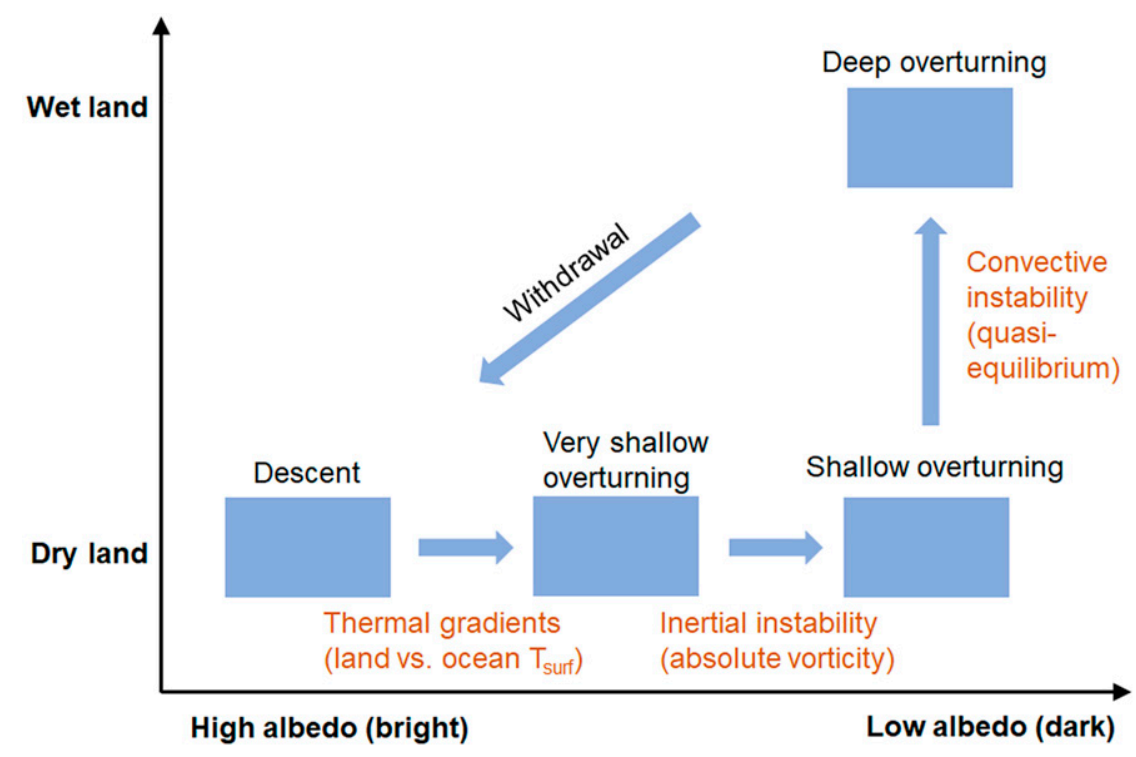

FIG. 10. A schematic overview of the monsoon circulation properties and relevant physical mechanisms across the land surface parameter space.

AM4 SON is most similar to $\mathrm{W} 0.26\left(F_{\text {net }}=64.3 \mathrm{~W} \mathrm{~m}^{-2}\right)$, but the W0.26 rainfall is nearly twice as strong $\left(7.84 \mathrm{~mm}\right.$ day $\left.^{-1}\right)$. When land surface moisture is limited, substantial moisture convergence from the ocean is needed to produce rainfall. In SON, the land heating is less pronounced than in the D suite and the circulation is substantially weaker, while the dry soil remains a limiting factor in generating precipitation.

The idealized experiments also exhibit seasonal hysteresis in the relationship between $F_{\text {net }}$ and precipitation, despite the fact that land surface moisture is externally controlled in D0.26 and W0.26. The seasonal cycle for D0.26 resembles that in AM4, though with reduced seasonal variability along both axes (Fig. 9a). This implies that the asymmetry between monsoon onset and withdrawal is due to the nature of the circulation, and is not entirely a consequence of seasonally varying land surface moisture availability or cloud radiative effects. Though $F_{\text {net }}$ decreases strongly from summer to fall, even dropping below zero in D0.26, the circulation persists and continues to support relatively high precipitation rates. Monsoon withdrawal follows an equatorward and off-continental shift of near-surface MSE and temperature maxima (not shown). Figure $9 \mathrm{~b}$ includes data for all four seasons of the D0.26, R0.26, and W0.26 experiments, and demonstrates a consistent relationship between near-surface $\theta_{e}$ and precipitation throughout the seasonal cycle. The near-surface MSE is consistently higher in the comprehensive GCM AM4, but the direct relationship between near-surface MSE and precipitation intensity holds throughout the seasonal cycle (Fig. 9b). While the net column heating varies directly with the strength of the summer monsoonal circulation, the near-surface $\theta_{e}$ is a better guide for capturing the monsoon-sector precipitation variability across seasons in both the idealized and comprehensive models. The near-surface $\theta_{e}$ contrast between the monsoon sector and the tropical mean also regulates the intensity of monsoon-sector precipitation throughout the seasonal cycle in the idealized experiments (Fig. 9c). As for the JFM data, substantial precipitation only occurs as the monsoon sector thermodynamic state approaches the tropical mean value. The strong relationships between precipitation and $\theta_{e}$ or contrasts thereof hold even in the dry land suite, when CQE conditions are not strictly satisfied. In AM4, the spring and fall deviate from the idealized model results, while the summer and winter values are remarkably consistent with the idealized model results (Fig. 9c).

The discrepancy between the monsoon onset season in AM4 (SON) and the idealized experiments is likely linked to the absence of one or more key processes from the idealized configuration. Connections between the idealized model simulations and AM4, or reality, must be drawn cautiously given the drastic simplification of the climate in the idealized experiments. The absence of global continental geometry impacts the general circulation in the idealized experiments, and much of the physics is greatly simplified. In particular, the effects of clouds on surface temperature, radiative fluxes (and thus $F_{\text {net }}$ ), and precipitation generation are noteworthy. Clouds might, for example, reduce surface temperatures over land and impede circulation strength in AM4 SON as compared to the idealized simulations with limited land moisture (e.g., Sharma et al. 1998).

The conclusions are largely robust to variations in the convective relaxation time scale, except that the ratio of largescale to convective rainfall depends strongly on this parameter. In the R0.26 $\tau_{\mathrm{BM}}$ experiments, the percentage of precipitation deriving from the SBM scheme is $88 \%$ in the control $\left(\tau_{\mathrm{BM}}=\right.$ $2 \mathrm{~h}$ ), $81 \%$ with $\tau_{\mathrm{BM}}=4 \mathrm{~h}, 71 \%$ with $\tau_{\mathrm{BM}}=8 \mathrm{~h}$, and only $36 \%$ when $\tau_{\mathrm{BM}}=16 \mathrm{~h}$. As expected, the near-surface relative humidity increases with the relaxation time, since the moisture profiles are less frequently relaxed via the convection scheme. The climate is otherwise robust to $\tau_{\mathrm{BM}}$, which has no notable impact on the total precipitation, nor on the region-mean 
surface temperature, OLR, net column energy flux, or moisture convergence $(P-E)$.

Figure 10 provides a schematic overview of the monsoonal properties and relevant mechanisms as land surface conditions are varied. At the highest land albedo values, a monsoon cannot develop regardless of the land moisture condition, resulting in mean descent. Over dry land at midrange land albedo values, a very shallow thermally driven monsoon develops. As land albedo decreases further, increasing the net column forcing and the cross-equatorial near-surface pressure gradient, inertial instability develops and leads to a deeper overturning cell. Deep convection can only develop when the land moisture constraint is relaxed, allowing latent heat fluxes to trigger convective instability. It is worthwhile to note that the shallow, thermally driven circulations resemble the regime described by Lindzen and Nigam (1987) in which boundary layer momentum dynamics play a crucial role. This view is supported by a set of perturbation experiments in which the land surface momentum roughness length is varied from $5 \times 10^{-5}$ to $0.5 \mathrm{~m}$ (its default value is $5 \times 10^{-3}$ ). When land surface roughness is increased by four orders of magnitude, precipitation increases strongly in D0.26 (+38\%), slightly less so in R0.26 (+32\%), and negligibly in W0.26 $(+3.7 \%)$.

The mechanisms at play in the idealized model simulations as land properties are modified may be relevant for the seasonal development of monsoons on Earth. Inertial instability alone is sufficient for producing a shallow but vigorous circulation and converging a large amount of moisture from the ocean. This mechanism may be key to monsoon onset following the dry season when soil moisture is low. Once the land is sufficiently moist, convective instability takes hold; the shallow circulation turns into a deep one. This mechanistic sequence is consistent with previous arguments (e.g., Fu et al. 1999) that wet season South American precipitation develops only after sufficient low-level moisture convergence reduces the convective inhibition.

In addition to elucidating the seasonal evolution of monsoon circulations, the idealized experiments indicate bounds on the range of land surface conditions that might support a monsoonal climate. When the net forcing is negative or the near-surface MSE is below the tropical mean value, a monsoon does not develop. It will be interesting to evaluate such threshold behavior in more realistic modeling settings. This can illuminate historical changes in tropical hydroclimate and provides a basis for understanding the how rising carbon dioxide levels may impact monsoons via their effect on land surface conditions.

Acknowledgments. Thanks to Spencer Clark for his help running the idealized moist model. We also thank Spencer Hill and Spencer Clark, developers of the "aospy" climate model analysis package for Python.

\section{REFERENCES}

Back, L., and C. Bretherton, 2006: Geographic variability in the export of moist static energy and vertical motion profiles in the tropical Pacific. Geophys. Res. Lett., 33, L17810, https:// doi.org/10.1029/2006GL026672.

Berg, A., and Coauthors, 2015: Interannual coupling between summertime surface temperature and precipitation over land: Processes and implications for climate change. J. Climate, 28, 1308-1328, https://doi.org/10.1175/JCLI-D-14-00324.1.

Boos, W. R., and T. Storelvmo, 2016: Near-linear response of mean monsoon strength to a broad range of radiative forcings. Proc. Natl. Acad. Sci. USA, 113, 1510-1515, https://doi.org/10.1073/ pnas.1517143113.

Bordoni, S., and T. Schneider, 2008: Monsoons as eddy-mediated regime transitions of the tropical overturning circulation. Nat. Geosci., 1, 515-519, https://doi.org/10.1038/ngeo248.

Bretherton, C. S., P. N. Blossey, and M. E. Peters, 2006: Interpretation of simple and cloud-resolving simulations of moist convectionradiation interaction with a mock-walker circulation. Theor. Comput. Fluid Dyn., 20, 421-442, https://doi.org/10.1007/ s00162-006-0029-7.

Byrne, M. P., and P. A. O'Gorman, 2013: Land-ocean warming contrast over a wide range of climates: Convective quasiequilibrium theory and idealized simulations. J. Climate, 26, 4000-4016, https://doi.org/10.1175/JCLI-D-12-00262.1.

— transpiration to climate warming: Why the "wet-get-wetter, dry-get-drier" scaling does not hold over land. J. Climate, $\mathbf{2 8}$, 8078-8092, https://doi.org/10.1175/JCLI-D-15-0369.1.

Chao, W. C., and B. Chen, 2001: The origin of monsoons. J. Atmos. Sci., 58, 3497-3507, https://doi.org/10.1175/1520-0469(2001) $058<3497$ :TOOM $>2.0$. CO 2 .

Charney, J. G., 1975: Dynamics of deserts and drought in the Sahel. Quart. J. Roy. Meteor. Soc., 101, 193-202, https://doi.org/ 10.1002/qj.49710142802.

— , and M. Stern, 1962: On the stability of internal baroclinic jets in a rotating atmosphere. J. Atmos. Sci., 19, 159-172, https://doi.org/ 10.1175/1520-0469(1962)019<0159:OTSOIB > 2.0.CO;2.

Chou, C., and J. D. Neelin, 2001: Mechanisms limiting the southward extent of the South American summer monsoon. Geophys. Res. Lett., 28, 2433-2436, https://doi.org/10.1029/ 2000GL012138.

$\longrightarrow$, and —, 2004: Mechanisms of global warming impacts on regional tropical precipitation. J. Climate, 17, 2688-2701, https:// doi.org/10.1175/1520-0442(2004)017<2688:MOGWIO > 2.0.CO;2.

Clark, S. K., Y. Ming, I. M. Held, and P. J. Phillipps, 2018: The role of the water vapor feedback in the ITCZ response to hemispherically asymmetric forcings. J. Climate, 31, 3659-3678, https://doi.org/10.1175/JCLI-D-17-0723.1.

$\longrightarrow,-$, and Á. F. Adames, 2020: Monsoon low pressure system-like variability in an idealized moist model. J. Climate, 33, 2051-2074, https://doi.org/10.1175/JCLI-D-19-0289.1.

Emanuel, K. A., 1995: On thermally direct circulations in moist atmospheres. J. Atmos. Sci., 52, 1529-1534, https://doi.org/ 10.1175/1520-0469(1995)052<1529:OTDCIM>2.0.CO;2.

_ J. D. Neelin, and C. S. Bretherton, 1994: On large-scale circulations in convecting atmospheres. Quart. J. Roy. Meteor. Soc., 120, 1111-1143, https://doi.org/10.1002/qj.49712051902.

Frierson, D. M., 2007: The dynamics of idealized convection schemes and their effect on the zonally averaged tropical circulation. J. Atmos. Sci., 64, 1959-1976, https://doi.org/10.1175/ JAS3935.1.

_- I. M. Held, and P. Zurita-Gotor, 2006: A gray-radiation aquaplanet moist GCM. Part I: Static stability and eddy scale. J. Atmos. Sci., 63, 2548-2566, https://doi.org/10.1175/ JAS3753.1. 
Fu, R., and W. Li, 2004: The influence of the land surface on the transition from dry to wet season in Amazonia. Theor. Appl. Climatol., 78, 97-110, https://doi.org/10.1007/s00704004-0046-7.

— B. Zhu, and R. E. Dickinson, 1999: How do atmosphere and land surface influence seasonal changes of convection in the tropical Amazon? J. Climate, 12, 1306-1321, https://doi.org/ 10.1175/1520-0442(1999)012<1306:HDAALS > 2.0.CO;2.

Garreaud, R., and P. Aceituno, 2001: Interannual rainfall variability over the South American Altiplano. J. Climate, 14, 2779-2789, https://doi.org/10.1175/1520-0442(2001)014<2779: IRVOTS $>2.0 . \mathrm{CO} ; 2$.

Geen, R., S. Bordoni, D. S. Battisti, and K. Hui, 2020: Monsoons, ITCZS and the concept of the global monsoon. Rev. Geophys., 58, e2020RG000700, https://doi.org/10.1029/2020RG000700.

Harrop, B. E., J. Lu, and L. R. Leung, 2019: Sub-cloud moist entropy curvature as a predictor for changes in the seasonal cycle of tropical precipitation. Climate Dyn., 53, 3463-3479, https:// doi.org/10.1007/s00382-019-04715-2.

Hill, S. A., 2019: Theories for past and future monsoon rainfall changes. J. Climate, 5, 160-171, https://doi.org/10.1007/s40641019-00137-8.

_- Y. Ming, I. M. Held, and M. Zhao, 2017: A moist static energy budget-based analysis of the Sahel rainfall response to uniform oceanic warming. J. Climate, 30, 5637-5660, https:// doi.org/10.1175/JCLI-D-16-0785.1.

Hsieh, J., and K. H. Cook, 2005: Generation of African easterly wave disturbances: Relationship to the African easterly jet. Mon. Wea. Rev., 133, 1311-1327, https://doi.org/10.1175/MWR2916.1.

Hurley, J., and W. Boos, 2013: Interannual variability of monsoon precipitation and local subcloud equivalent potential temperature. J. Climate, 26, 9507-9527, https://doi.org/10.1175/ JCLI-D-12-00229.1.

Kodama, Y.-M., 1992: Large-scale common features of subtropical precipitation zones (the Baiu frontal zone, the SPCZ, and the SACZ) Part I: Characteristics of subtropical frontal zones. J. Meteor. Soc. Japan, 70, 813-836, https://doi.org/10.2151/ jmsj1965.70.4_813.

__ 1993: Large-scale common features of sub-tropical convergence zones (the Baiu frontal zone, the SPCZ, and the SACZ) Part II: Conditions of the circulations for generating the STCZS. J. Meteor. Soc. Japan, 71, 581-610, https://doi.org/ 10.2151/jmsj1965.71.5_581.

Koster, R. D., and Coauthors, 2004: Regions of strong coupling between soil moisture and precipitation. Science, 305, 11381140, https://doi.org/10.1126/science.1100217.

Levine, X. J., and W. R. Boos, 2017: Land surface albedo bias in climate models and its association with tropical rainfall. Geophys. Res. Lett., 44, 6363-6372, https://doi.org/10.1002/ 2017 GL072510.

Lindzen, R. S., and S. Nigam, 1987: On the role of sea surface temperature gradients in forcing low-level winds and convergence in the tropics. J. Atmos. Sci., 44, 2418-2436, https://doi.org/ 10.1175/1520-0469(1987)044<2418:OTROSS > 2.0.CO;2.

Manabe, S., 1969: Climate and the ocean circulation: I. The atmospheric circulation and the hydrology of the earth's surface. Mon. Wea. Rev., 97, 739-774, https://doi.org/10.1175/15200493(1969)097<0739:CATOC $>2.3$. CO 2 .

Maroon, E. A., and D. M. Frierson, 2016: The impact of a continent's longitudinal extent on tropical precipitation. Geophys. Res. Lett., 43, 11-921, https://doi.org/10.1002/2016GL071518.

Neelin, J. D., 2007: Moist dynamics of tropical convection zones in monsoons, teleconnections, and global warming. The Global
Circulation of the Atmosphere, T. Schneider and A. H. Sobel, Eds., Princeton University Press, 267-301.

- and I. Held, 1987: Modeling tropical convergence based on the moist static energy budget. Mon. Wea. Rev., 115, 3-12, https:// doi.org/10.1175/1520-0493(1987)115<0003:MTCBOT>2.0.CO;2.

Nie, J., W. R. Boos, and Z. Kuang, 2010: Observational evaluation of a convective quasi-equilibrium view of monsoons. J. Climate, 23, 4416-4428, https://doi.org/10.1175/ 2010JCLI3505.1.

Nieto Ferreira, R., and W. C. Chao, 2013: Aqua-planet simulations of the formation of the South Atlantic convergence zone. Int. J. Climatol., 33, 615-628, https://doi.org/10.1002/joc.3457.

Paynter, D., and V. Ramaswamy, 2014: Investigating the impact of the shortwave water vapor continuum upon climate simulations using GFDL global models. J. Geophys. Res., 119, 10 720-10 737, https://doi.org/10.1002/2014JD021881.

Plumb, R. A., and A. Y. Hou, 1992: The response of a zonally symmetric atmosphere to subtropical thermal forcing: Threshold behavior. J. Atmos. Sci., 49, 1790-1799, https://doi.org/10.1175/ 1520-0469(1992)049<1790:TROAZS > 2.0.CO;2.

Privé, N. C., and R. A. Plumb, 2007a: Monsoon dynamics with interactive forcing. Part I: Axisymmetric studies. J. Atmos. Sci., 64, 1417-1430, https://doi.org/10.1175/JAS3916.1.

— and 2007b: Monsoon dynamics with interactive forcing. Part II: Impact of eddies and asymmetric geometries. J. Atmos. Sci., 64, 1431-1442, https://doi.org/10.1175/JAS3917.1.

Schwingshackl, C., M. Hirschi, and S. I. Seneviratne, 2018: A theoretical approach to assess soil moisture-climate coupling across CMIP5 and GLACE-CMIP5 experiments. Earth Syst. Dyn., 9, 1217-1234, https://doi.org/10.5194/esd-9-1217-2018.

Seneviratne, S. I., T. Corti, E. L. Davin, M. Hirschi, E. B. Jaeger, I. Lehner, B. Orlowsky, and A. J. Teuling, 2010: Investigating soil moisture-climate interactions in a changing climate: A review. Earth-Sci. Rev., 99, 125-161, https://doi.org/10.1016/ j.earscirev.2010.02.004.

Sharma, O., H. Le Treut, G. Seze, L. Fairhead, and R. Sadourny, 1998: Interannual variations of summer monsoons: Sensitivity to cloud radiative forcing. J. Climate, 11, 1883-1905, https:// doi.org/10.1175/1520-0442-11.8.1883.

Skinner, C. B., and N. S. Diffenbaugh, 2014: Projected changes in African easterly wave intensity and track in response to greenhouse forcing. Proc. Natl. Acad. Sci. USA, 111, 68826887, https://doi.org/10.1073/pnas.1319597111.

Smyth, J. E., and Y. Ming, 2020: Characterizing drying in the South American monsoon onset season with the moist static energy budget. J. Climate, 33, 9735-9748, https://doi.org/10.1175/ JCLI-D-20-0217.1.

— S. Hill, and Y. Ming, 2018: Simulated responses of the West African monsoon and zonal-mean tropical precipitation to early holocene orbital forcing. Geophys. Res. Lett., 45, 12 04912 057, https://doi.org/10.1029/2018GL080494.

Tomas, R. A., and P. J. Webster, 1997: The role of inertial instability in determining the location and strength of nearequatorial convection. Quart. J. Roy. Meteor. Soc., 123, 1445-1482, https://doi.org/10.1002/qj.49712354202.

Vallis, G. K., and Coauthors, 2018: Isca, v1.0: A framework for the global modelling of the atmospheres of Earth and other planets at varying levels of complexity. Geosci. Model Dev., 11, 843-859, https://doi.org/10.5194/gmd-11843-2018.

van der Wiel, K., A. J. Matthews, D. P. Stevens, and M. M. Joshi, 2015: A dynamical framework for the origin of the diagonal South Pacific and South Atlantic convergence zones. Quart. 
J. Roy. Meteor. Soc., 141, 1997-2010, https://doi.org/10.1002/ qj. 2508 .

Voigt, A., S. Bony, J.-L. Dufresne, and B. Stevens, 2014: The radiative impact of clouds on the shift of the intertropical convergence zone. Geophys. Res. Lett., 41, 4308-4315, https:// doi.org/10.1002/2014GL060354.

Walker, J. M., S. Bordoni, and T. Schneider, 2015: Interannual variability in the large-scale dynamics of the South Asian summer monsoon. J. Climate, 28, 3731-3750, https://doi.org/ 10.1175/JCLI-D-14-00612.1.

Wang, H., and R. Fu, 2004: Influence of cross-Andes flow on the South American low-level jet. J. Climate, 17, 1247-1262, https://doi.org/10.1175/1520-0442(2004)017<1247:IOCFOT> 2.0.CO;2.
Zhai, J., and W. Boos, 2015: Regime transitions of cross-equatorial Hadley circulations with zonally asymmetric thermal forcings. J. Atmos. Sci., 72, 3800-3818, https://doi.org/10.1175/JAS-D15-0025.1.

Zhang, Y., and S. Fueglistaler, 2020: How tropical convection couples high moist static energy over land and ocean. Geophys. Res. Lett., 47, e2019GL086387, https://doi.org/ 10.1029/2019GL086387.

Zhisheng, A., and Coauthors, 2015: Global monsoon dynamics and climate change. Annu. Rev. Earth Planet. Sci., 43, 29-77, https:// doi.org/10.1146/annurev-earth-060313-054623.

Zhou, W., and S.-P. Xie, 2018: A hierarchy of idealized monsoons in an intermediate GCM. J. Climate, 31, 9021-9036, https:// doi.org/10.1175/JCLI-D-18-0084.1. 